\title{
Consequences of human Tau aggregation in the hippocampal formation of ageing mice in vivo
}

Tim J. Viney ${ }^{1 *}$, Barbara Sarkany ${ }^{1}$, A. Tugrul Ozdemir ${ }^{1}$, Katja Hartwich ${ }^{1,2}$, Judith Schweimer ${ }^{1}$, David Bannerman ${ }^{3}$, Peter Somogyi ${ }^{1}$.

${ }^{1}$ Department of Pharmacology, University of Oxford, Oxford, UK.

2Current address: Medical Research Council Brain Network Dynamics Unit, Nuffield Department of Clinical Neurosciences, University of Oxford, Oxford, UK.

${ }^{3}$ Department of Experimental Psychology, University of Oxford, Oxford, UK.

*Correspondence: tim.viney@pharm.ox.ac.uk

\section{Abstract}

Intracellular aggregation of hyperphosphorylated Tau (pTau) in the brain is associated with cognitive and motor impairments, and ultimately neurodegeneration. We investigate how human pTau affects cells and network activity in the hippocampal formation of THYTau22 tauopathy model mice in vivo. We find that pTau preferentially accumulates in deeplayer pyramidal neurons, leading to neurodegeneration, and we establish that pTau spreads to oligodendrocytes. During goal-directed virtual navigation in aged transgenic mice, we detect fewer high-firing pyramidal cells, with the remaining cells retaining their coupling to theta oscillations. Analysis of network oscillations and firing patterns of pyramidal and GABAergic neurons recorded in head-fixed and freely-moving mice suggests preserved neuronal coordination. In spatial memory tests, transgenic mice have reduced short-term familiarity but spatial working and reference memory are surprisingly normal. We hypothesize that unimpaired subcortical network mechanisms implementing cortical neuronal coordination compensate for the widespread pTau aggregation, loss of high-firing cells and neurodegeneration.

\section{Introduction}

The majority of tauopathies, defined by intracellular accumulation of hyperphosphorylated Tau proteins (pTau), are 'sporadic', and a minority are inherited, caused by mutations of the microtubule-associated protein Tau (MAPT) gene (Goedert et al., 2017). Humans express six isoforms, with 3 containing three repeats (3R) each and 3 others containing four repeats (4R) each (Goedert et al., 2017). Their isoform provides an indication of the kinds of affected neurons and glia as well as the spatiotemporal distribution in the brain. Alzheimer's disease, amyotrophic lateral sclerosis, Niemann-Pick disease type $C$ and some types of familial frontotemporal dementia and parkinsonism (FTDP) have a mixture of $3 R$ and $4 R$ Tau. Those with only 3R Tau include Pick's disease and some types of FTDP. The 4R tauopathies include corticobasal degeneration (CBD), progressive supranuclear palsy (PSP), argyrophilic grain disease, and other types of FTDP (Arakhamia et al., 2020; Goedert et al., 2017). The impact on cognitive and motor functions depend on which brain regions and cell types are most vulnerable to developing pTau aggregates and the extent of neurodegeneration. Deficits in spatial (or episodic) memory - our ability to encode and recall environmental contexts - are strongly associated with cortical pTau-related progression from mild cognitive impairment to Alzheimer's disease (Moscoso et al., 2019; Vogel et al., 2020; Wilson et al., 2011). It is generally 
accepted that spread of pTau correlates with severity of neurological symptoms, with age being the greatest risk factor.

Animal models provide a wealth of information about the impact of pTau on various aspects of behavior, cognition, network excitability and plasticity. Many models suffer from progressive motor impairments, making it difficult to perform investigations using physiologically-relevant aged animals. We investigated how aggregation of mutant human $4 \mathrm{R}$ Tau affected spatial memory and neuronal coordination (spatio-temporal organization of neuronal activity) in awake behaving mice at different ages using the THY-Tau22 mouse line, which does not develop motor impairments (Schindowski et al., 2006). Heterozygous transgenic (tg) mice display prominent 'neurofibrillary tangles' (accumulation of human pTau in neuronal somata) as well as 'neuropil threads' (pTau in other processes such as axons). We found that ageing tg mice had hippocampal neurodegeneration, fewer high-firing complex spiking cells, and exhibited reduced short-term familiarity for spatial cues. Despite these changes, neuronal coupling to theta oscillations and spatial working and reference memory performance showed no detectable differences. We hypothesize that this is attributed to unimpaired network mechanisms that govern cortical neuronal coordination.

\section{Results}

Distribution of neurofibrillary tangles in ageing mice

To understand how pTau aggregation affects neuronal and network activity, we first mapped pTau in brains of tg mice at different ages. At 2-3 months old (mo), clusters of AT8 immunoreactive (pTau+) neurons were observed in dorsal subiculum (SUBd) and basolateral amygdala (BLA) (Fig. 1a,b; n=2/2 mice). Septo-dorsal hippocampal CA1 (CA1d) contained few pTau+ pyramidal neurons. The medial prefrontal cortex (mPFC) lacked pTau, in contrast to adjacent motor cortex (Fig. 1c). By 4-6 mo, pTau was observed in more neurons and widely in SUBd and CA1d (Fig 1a, n=5/5 mice). In some mice we observed pTau+ mossy fibers of dentate gyrus (DG) granule cells (Fig. S1a). By 8-10 mo, when hippocampal-dependent memory deficits were reported previously (Schindowski et al., 2006; Van der Jeugd et al., 2013), extensive pTau was found in distal CA1d and adjacent (proximal) SUBd (Fig 1a; n=2/2 mice), also called 'prosubiculum' (Ding et al., 2020), which showed abundant neuropil threads. A few DG granule cells in the septal pole were also pTau+. The pattern was broadly similar at 13-16 mo ( $n=4 / 4$ mice) and 18-24 mo ( $n=9 / 9$ mice) save for an apparent reduction in pTau+ somata along with an increase in neuropil threads. At these stages the DG contained more pTau but CA3 remained relatively unaffected. In the mPFC, the few pTau+ cells were distributed in deep layers. The BLA consistently exhibited a high density of pTau in aged mice. In isocortex, pTau was predominantly found in layer 5 pyramidal neurons (Fig. 1d, Fig. S1b). In non-transgenic (ntg) littermates, pTau was not observed ( $\mathrm{n}=16 / 16$ mice, 2-24 mo). Lipofuscin fluorescence was detected in all aged mice. In summary, the distribution in the hippocampal formation, isocortex and amygdala is broadly similar to previous reports (Degiorgis et al., 2020; Schindowski et al., 2006; Van der Jeugd et al., 2013).

In contrast to the neuronal pTau distribution described above (Figs. 1a-d, S2), key subcortical areas linked to generating theta frequency rhythmic activity (important for coordination of neuronal activity) were unaffected, including the anterior and midline thalamus, medial septum (Fig. 1e, S1b,c), mammillary bodies, and supramammillary nucleus. Other areas of the hypothalamus, and basal ganglia, were also largely unaffected (Fig. S1). In the brainstem, 
neuronal pTau was found in the red nucleus, deep layers of the superior colliculus, periaqueductal gray, and pontine nuclei, but not in the raphe nuclei, ventral tegmental area, substantia nigra, or interpeduncular nucleus (from $n=4 / 4 \mathrm{tg}$ mice, 16-23 mo). We could not detect any dopaminergic pTau+ neurons in the brainstem (lacked tyrosine hydroxylase immunoreactivity). Furthermore, pTau+ axons were prominent in the fimbria and thalamic reticular nucleus, most likely originating from affected hippocampal/cortical neurons (Fig. S1). Similarly, axons in lateral septum most likely originated from hippocampal pTau+ cells (Fig. 1e).

\section{Deep-layer CA1 pyramidal neurons preferentially accumulate pTau}

The hippocampal CA1 region is critical for spatial/episodic memory and contains place cells. Neurons containing pTau were immunoreactive for CTIP2, SATB2, and Wfs1, which are markers of CA1 pyramidal cells (Lapray et al., 2012; Valero et al., 2015) (n=50/51 pTau+ SATB2+ CA1d cells, n=3 mice; Fig. 2a-c). Immunoreactivity for Wfs1 was extremely low compared to nearby unaffected neurons and was localized to the plasma membrane $(n=11 / 23$ CA1d cells weakly immunopositive, $n=12 / 23$ undetectable; Fig. 2c, S2a), suggesting that Tau tangles affect Wfs1 levels (Sakakibara et al., 2018).

The upper, compact sublayer of stratum pyramidale (SP) primarily consists of calbindin immunopositive $(\mathrm{CB}+)$ neurons, and the lower sublayer neurons are mostly $\mathrm{CB}$ immunonegative (CB-, lacking detectable levels of CB) (Sanchez-Aguilera et al., 2021; Valero et al., 2015). Interestingly, pTau+ CA1 SP neurons were mostly found in the deep sublayer and were $\mathrm{CB}^{-}(\mathrm{n}=0 / 14 \mathrm{CB}+$ pTau+ cells from 1 mouse; Figs. $2 \mathrm{~d}, 1 \mathrm{a})$. Cells that were pTau+ were also immunonegative for parvalbumin (PV) and calretinin (CR) $(n=0 / 36 \mathrm{PV}+$ or $\mathrm{CR}+$ cells from 2 mice), which mark subpopulations of GABAergic neurons. We confirmed neurofibrillary tangles in pyramidal neurons by electron microscopy (Fig. 2e). Thus, pTau preferentially accumulated in $\mathrm{CB}-$ pyramidal neurons.

There is previous evidence of a general loss of CA1 cells in tg mice over 12 mo (Schindowski et al., 2006). To determine whether this was due to a loss of pyramidal neurons, we counted SATB2+ nuclei along CA1d SP; SATB2 was not detectable in CA2 or SUBd pyramidal neurons. The CA1 SP was markedly thinner, particularly towards SUBd, where the most tangles and threads were observed (Figs. 2f-h, 1a). Pyramidal cells were fewer in $22 \mathrm{mo}$ tg mice compared to aged-matched ntg mice ( $34 \%$ reduction, $t_{(4)}=20.6, P<0.0001 ; n=3$ ntg and $n=3$ tg mice; Fig. $2 \mathrm{~h})$. Thus, we suggest the accumulation of pTau in pyramidal neurons leads to neurodegeneration.

\section{Spread of pTau to oligodendrocytes}

In older (15-23 mo, $\mathrm{n}=6$ ) but not younger (4-5 mo, $\mathrm{n}=4)$ tg mice, we observed coiled bodies intensely AT8 immunoreactive 'flame-like' rings of pTau - in many brain regions, especially in white matter tracts containing pTau+ axons (Figs. 3, S3), such as the fimbria, fornix, alveus, dorsal hippocampal commissure, corpus callosum, and stria terminalis. Coiled bodies were also in hippocampal stratum oriens, the subicular complex, granular retrosplenial cortex (Fig. S3), parts of neocortex, dorsal striatum, and were similar in appearance to those found but not widely recognized in Alzheimer's disease (Nishimura et al., 1995). The anterior thalamus and mammillary bodies had scattered coiled bodies. In the brainstem, the substantia nigra pars reticulata, ventral tegmental area, pontine nuclei and the interpeduncular nucleus contained coiled bodies, a pathology found in 4R tauopathies such as CBD and PSP (Arima, 1996; Arima et al., 1997). 
Coiled bodies colocalized with Olig2, an oligodendrocyte transcription factor (Figs. 3, S3e,f). Smaller coils (<2 $\mu \mathrm{m}$ diameter) associated with Olig2-immunoreactive nuclei (Fig. 3c) may represent densely packed pTau. Olig2 was not observed in pTau+ neurons (Fig. S3e). We confirmed the presence of pTau+ filament bundles in oligodendrocytes using electron microscopy (Fig. 3e) (Lin et al., 2003; Peters and Sethares, 2004). To our knowledge, the Thy1 promoter is not active in oligodendrocytes (Caroni, 1997). As coiled bodies were not observed in younger mice, despite accumulation of pTau in neurons at all ages investigated (Fig. 1), we suggest that pTau might spread from neurons to oligodendrocytes via the pTau-containing axons (Fig. 3).

\section{Reduced short-term familiarity but unimpaired spatial reference and working memory}

To test the effects of pTau accumulation and neurodegeneration, we assessed short-term hippocampal-dependent spatial memory (age range, 13-24 mo; median 15 [interquartile range 4] mo ntg, and 14 [5] mo tg mice) using a spontaneous spatial novelty preference Y-maze task (Fig. 4a). Mice initially explored two arms (start arm and other arm); the third (novel) arm was blocked off. After $5 \mathrm{~min}$, the block was removed, enabling mice to explore all three arms. The total distance mice covered in the exposure phase was similar for both genotypes (mean 1.78 \pm s.d. $0.61 \mathrm{~m}$ for $\mathrm{n}=18 \mathrm{ntg}$ mice versus $1.75 \pm 0.45 \mathrm{~m}$ for $\mathrm{n}=15 \mathrm{tg}$ mice; $t_{(31)}=0.1635, P=0.8712$; Fig. $4 a$, middle), indicating tg mice were not hyper- or hypoactive. Discrimination ratios (time in novel over total time in novel and other arms) were significantly different $(0.64 \pm 0.10$ for $\mathrm{n}=22 \mathrm{ntg}$ mice versus $0.52 \pm 0.16$ for $\mathrm{n}=20 \mathrm{tg}$ mice; $t_{(40)}=2.9637, P=0.0058$; Fig. 4 a right). This was explained by ntg mice spending more time in the novel arm compared to chance $\left(t_{(21)}=\right.$ 6.6435, $P<0.0001 ; 110 \pm 27 \mathrm{~s}$ in the novel arm, $61 \pm 22 \mathrm{~s}$ in the other arm), as expected for wild type animals (Bannerman et al., 2008). The $\operatorname{tg}$ mice failed to discriminate $\left(t_{(19)}=0.4840, P=\right.$ $0.6339 ; 84 \pm 25 \mathrm{~s}$ in the novel arm, $85 \pm 45 \mathrm{~s}$ in the other arm), consistent with previous studies reporting spatial novelty preference impairment in younger tg mice (Belarbi et al., 2011; Van der Jeugd et al., 2011).

To evaluate aversive spatial reference memory, we tested mice in a hippocampal-dependent water escape Y-maze task (Lyon et al., 2011; Pritchett et al., 2016; Sri et al., 2019). Mice navigated from one of two pseudorandomly allocated start arms to a hidden platform at the end of a fixed goal arm (Fig. 4b). We tested 14 mo mice for $10 \mathrm{~d}$ (blocks of 5 trials/d), then conducted a probe test on day 11. Mice of both genotypes learned the location of the hidden platform. Tg mice performed similarly to ntg littermates during acquisition training (choice accuracy, repeated-measures two-way ANOVA: genotype $F_{(1,9)}=0.1123, P=0.7452$; training block $F_{(9,81)}=6.809, P=0.0026$; genotype $\mathrm{x}$ training block, $F_{(9,81)}=0.9458, P=0.4908$; Fig. $4 \mathrm{~b}$ middle; one ntg mouse was excluded as it failed to make choices after day 3). On day 11, we removed the hidden platform and let mice swim freely for $60 \mathrm{~s}$ (probe trial). We found no difference $(58.6 \pm 9.68 \%$ of time in the goal arm for $n=4$ ntg mice vs $64.56 \pm 15.96 \%, n=7 \mathrm{tg}$ mice; $t_{(9)}=0.6660, p=0.5221$; Fig. $4 \mathrm{~b}$ right). In summary, based on this task we could not detect deficits in aversive spatial reference memory.

We tested spatial working memory in a non-matching to place T-maze task (Reisel et al., 2002). Mice were forced to choose a rewarded goal arm by the presence of a block (forced run), followed by a choice run whereby they could visit the previously blocked goal arm to receive another reward or the previously visited arm which was now unrewarded (alternation; Fig. 4c). We tested mice at 4,7 and $12 \mathrm{mo}(\mathrm{n}=11 \mathrm{ntg}$ and $\mathrm{n}=16 \mathrm{tg}$ mice; within-subject, longitudinal design) under mild food restriction to $90.7 \pm 2.7 \%$ of their free-feeding weight. Behavioral 
performance improved with training (alternation score, repeated-measures ANOVA: training block $F_{(9,225)}=8.497, P<0.001$; Fig. $4 \mathrm{c}$ ), independent of age and genotype (age $F_{(2,50)}=0.534, P$ $=0.590$; genotype $F_{(1,25)}=0.295, P=0.592$; age $x$ genotype $\left.F_{(2,50)}=0.024, P=0.976\right)$, with an overall similar performance across blocks (age $\mathrm{x}$ block $\mathrm{x}$ genotype $F_{(18,450)}=0.522, P=0.948$; Fig. 4c). Improvements in correctly alternating on the choice run occurred at all ages (Fig. 4c). All training was carried out within the same context; a new context would require mice to form new spatial maps, which might reveal differences in genotypes. One cohort ( $\mathrm{n}=6 \mathrm{ntg}$ and $\mathrm{n}=9 \mathrm{tg}$ mice) was re-tested at 13 mo in a different context (see Methods). Mice approached a high alternation score by the $5^{\text {th }}$ block for both genotypes (Fig. S4a).

During T-maze training we noticed that many mice would wait at the end of the start arm before voluntarily initiating a run. Strikingly, tg mice waited significantly longer than ntg mice before initiating their choice run (4 mo: 4.6 [3.9] s for $\mathrm{ntg}$ mice, 10.2 [11.1] s for $\mathrm{tg}$ mice, $U=41, P=0.0218 ; 7 \mathrm{mo}, 1.0(4.1) \mathrm{ntg}, 9.3(12.3) \mathrm{s} \mathrm{tg}, U=23.5, P=0.0016 ; 12 \mathrm{mo}, 5.1$ (7.9) s ntg, 13.5 (14.0) tg, $U=38, P=0.0145 ;$ Fig. $4 \mathrm{~d})$. However, this was also the case for the forced run (4 mo, 1.8 [1.4] s ntg, 3.8 [3.5] s tg, $U=40, P=0.0191 ; 7 \mathrm{mo}, 0.5$ [1.3] s ntg, 3.2 [5.3] s tg, $U=29.5$, $P=0.0042 ; 12 \mathrm{mo}, 1.5$ [3.1] s ntg, 6.9 [12.0] s tg, $U=34.5, P=0.0089 ;$ Fig. S4b), suggesting the delay is not directly related to decisions. Although ntg and tg mice had similar delay times in the first session (block 1), they rapidly diverged over subsequent days (Figs. $4 \mathrm{~d}$, S4b). Once mice left the end of the start arm, actual run times were similar, suggesting unimpaired ambulation (Fig. S4c). Therefore, despite tg mice taking longer to initiate both forced and choice runs, we did not detect a spatial working memory impairment in this task.

Mice were also placed in an elevated plus maze, an ethological test of unconditioned anxiety featuring two closed and two open arms. Wild type rodents spend more time in closed arms, and time in open arms is increased in rats with ventral (temporal) hippocampal lesions (Bannerman et al., 2004; Kjelstrup et al., 2002); this region was also enriched with pTau in tg mice (not shown). In 3 mo mice, tg mice spent a significantly greater proportion of time in open arms than ntg mice (17.1 [13.7] \% of time in open arms for $\mathrm{n}=9 \mathrm{ntg}$ mice versus 58.3 [29.9] $\%$ for $\mathrm{n}=5 \mathrm{tg}$ mice; $U=45, P=0.00216$ ), consistent with previous reports at $6 \mathrm{mo}$ (Schindowski et al., 2006). There was also a slight difference in arm entries (12 [4.25] entries for $9 \mathrm{ntg}$ mice versus 19 [7] for $5 \mathrm{tg}$ mice; $U=8, P=0.0448$; Fig. 4e). In a separate cohort of 12 mo mice that had been extensively handled and tested in other behavioral tasks (but were naïve to the plus maze), ntg mice ( $n=11)$ spent 46.9 [16.4] \% of time in open arms compared to 75.2 [34.0] \% for $\operatorname{tg}$ mice $(n=16)(U=142, P=0.0083$; Fig. $4 \mathrm{e})$. Taken together, we conclude that pTau aggregation affects short-term familiarity and anxiety-related activity but leaves spatial reference and working memory unimpaired.

\section{Network oscillations are largely unaffected by hippocampal pTau}

To determine whether intracellular pTau affects neuronal and network activity, we used glass electrodes to record network oscillations and single neurons in the hippocampal formation of both awake head-fixed and freely moving aged mice. We first focused on 5-12 Hz theta oscillations, which reflect coordination of neuronal activity (Ahnaou et al., 2017; Csicsvari et al., 1999; Menkes-Caspi et al., 2015; Wang et al., 2015) required for spatial memory. We targeted the prosubiculum, corresponding to distal CA1d (close to SUBd) (Ding et al., 2020), where most Tau tangles and threads were observed (Fig. 1a). Prominent theta oscillations were observed in head-fixed mice of both genotypes while they ran on a running disc (Fig. $5 a)$, with similar peak theta frequency values for slow running speeds $(4-6 \mathrm{~cm} / \mathrm{s} ; 6.35 \pm 0.59$ 
$\mathrm{Hz} \mathrm{ntg}, \mathrm{n}=3$ mice, $18-24$ mo; $7.05 \pm 0.89 \mathrm{~Hz}$ tg, $\mathrm{n}=4$ mice, $13-18$ mo; $\left.t_{(5)}=1.162, P=0.2978\right)$. At faster running speeds, we found that tg mice had a slightly higher theta peak frequency than $n t g$ mice $\left(6-10 \mathrm{~cm} / \mathrm{s} ; 6.70 \pm 0.45 \mathrm{~Hz}\right.$ ntg versus $\left.7.45 \pm 0.26 \mathrm{~Hz} \operatorname{tg} ; t_{(5)}=2.840, P=0.0362\right)$. However, in a different context involving trained water-restricted aged mice running on an air-suspended jet ball along a virtual linear track, the theta peak was similar for both genotypes $\left(6.80 \pm 0.16 \mathrm{~Hz} n t g, n=3\right.$ mice, $22-24 \mathrm{mo} ; 6.38 \pm 0.27 \mathrm{~Hz}$ tg, $\mathrm{n}=3$ mice, $22 \mathrm{mo} ; t_{(4)}=$ $2.324, p=0.0808$; Fig. 5a). These data suggest that the sampled theta frequency oscillations are largely unaffected by pTau.

In order to investigate potential changes in network oscillations more closely, we compared the spectral content of local field potentials (LFPs) using empirical mode decomposition (EMD), which is more appropriate for the non-linear non-stationary signals (Lopes-DosSantos et al., 2018; Quinn et al., 2021). We sampled LFPs recorded with glass electrodes for movement periods as above and used masked EMD to obtain intrinsic mode functions (IMFs, see Methods). Theta corresponded to IMF6 (Fig. 5c) with a mean instantaneous frequency (IF) of $7.4 \pm 0.6 \mathrm{~Hz}$ in ntg mice $(\mathrm{n}=3)$ and $7.3 \pm 0.5 \mathrm{~Hz}$ in $\mathrm{tg}$ mice $(\mathrm{n}=4)$. We detected slow-gamma (IMF4), mid-gamma (IMF3) and fast-gamma (IMF2) oscillations (Fig. 5c,d), with similar distributions for both genotypes (IMF4, $28.6 \pm 0.9 \mathrm{~Hz}$ for $\mathrm{n}=3 \mathrm{ntg}$ mice, $29.4 \pm 0.8 \mathrm{~Hz}$ for $\mathrm{n}=4$ $\operatorname{tg}$ mice; IMF3, $56.3 \pm 0.8 \mathrm{~Hz}$ for $\mathrm{n}=2 \mathrm{ntg}$ mice, $58.6 \pm 4.5 \mathrm{~Hz}$ for $\mathrm{n}=4 \mathrm{tg}$ mice; IMF2, $141.4 \pm 8.1$ $\mathrm{Hz}$ for $\mathrm{n}=3 \mathrm{ntg}$ mice, $134.7 \pm 15.3 \mathrm{~Hz}$ for $\mathrm{n}=4 \mathrm{tg}$ mice; Fig. $5 \mathrm{~d}$ ). Similar results were found for mice running along the virtual linear track (Fig. S5a).

Higher frequency oscillations are typically coupled to phases of slower oscillations such as theta in rodents and humans (Canolty et al., 2006; Lopes-Dos-Santos et al., 2018). Impaired phase-amplitude coupling has previously been attributed to pTau in mouse models (Ahnaou et al., 2017) and is altered in mild cognitive impairment and Alzheimer's disease (Goodman et al., 2018). Mid-gamma is associated with entorhinal inputs to CA1 superficial apical dendrites, detectable in CA1d SP at the peak of theta cycles in rodents (Lasztoczi and Klausberger, 2017). Despite neurodegeneration and pTau (Fig. 2f-h), for recordings with good signal to noise ratios, higher amplitude mid-gamma oscillations were detected close to the theta peak ( $\mathrm{n}=5 / 5 \mathrm{tg}$ mice, 13-23 mo; Fig. 5e). Similar results were observed in ntg mice $(n=3 / 3,22-24 \mathrm{mo})$. Furthermore, in mice running along the virtual linear track, we could detect weak modulation of fast-gamma close to the theta trough $(n=3 / 3$ ntg and $n=2 / 2$ tg mice; Fig. S5b,c). Theta frequency was typically lower during the peak-to-descending phase of theta oscillations (Fig. 5e, Fig. S5b,c).

Memory consolidation is associated with another form of cross frequency coupling: the sharp wave ripple (SWR) complex, consisting of $130-230 \mathrm{~Hz}$ ripple oscillations occurring during $~ 30-$ $120 \mathrm{~ms}$ sharp waves (Buzsaki, 2015). We detected ripples from CA1d SP in aged ntg and tg mice while they rested on the running disc (head-fixed) or in an open field. We found no difference between $\mathrm{ntg}(\mathrm{n}=3,18-24 \mathrm{mo})$ and $\operatorname{tg}(\mathrm{n}=4,13-18 \mathrm{mo})$ mice in terms of ripple frequency $(124.7 \pm 4.9 \mathrm{~Hz} \mathrm{ntg}, 126.2 \pm 5.4 \mathrm{~Hz} \mathrm{tg})$, ripple duration $(53.1 \pm 4.6 \mathrm{~ms} \mathrm{ntg}, 51.9 \pm 2.7$ $\mathrm{ms} \mathrm{tg})$, or ripple cycle counts $(6.6 \pm 0.7 \mathrm{ntg}, 6.6 \pm 0.5 \mathrm{tg})$. Sharp wave polarity changed with depth, with positive deflections in strata oriens and pyramidale, followed by negative sharp waves in superficial SP and stratum radiatum (data not shown). This suggests that the sampled CA1d SWRs are unaffected by pTau in these aged tg mice. In summary, our analysis of network oscillations suggests unimpaired neuronal coordination in the hippocampus, 
consistent with good performance in the hippocampal-dependent spatial working and reference memory tasks.

Firing patterns of single hippocampal neurons are similar in tg and ntg mice

Next we asked whether pTau affected activity of individual neurons. We extracellularly recorded 65 hippocampal neurons with glass electrodes under freely moving or head-fixed conditions ( $\mathrm{n}=17$ mice, 5-27.6 mo; Fig. 6) classified as putative principal cells ( $\mathrm{n}=14$ from $\mathrm{ntg}$ and wt mice; $n=25$ from tg mice; Fig. $6 a, c)$ or interneurons ( $n=6$ from $n t g$ mice, $n=20$ from tg mice). At the end of each recording session, we attempted juxtacellular labeling for post hoc identification and to confirm recording locations. We recovered 11 neurons, including 5 pyramidal neurons and 3 interneurons from tg mice. Of the identified neurons from $\mathrm{tg}$ mice, 4/4 tested pyramidal cells and all interneurons lacked pTau immunoreactivity (Fig. 6d,e). Identified pyramidal cells were immunopositive for CTIP2, similar to cells in ntg mice and pTau+ cells in tg mice (Figs. 6b,e, 2a).

Under both freely moving and head-fixed conditions, pyramidal neurons were recognized by relatively wide isolated spikes and complex spike bursts (Fig. 6c) that were indistinguishable across genotypes (Fig. 6a). Most recordings (69\% of recorded cells) were targeted to prosubiculum due to the high density of pTau (Fig. 1a); the remainder were sampled in more medial CA1, the DG or CA3. Of principal neurons with firing rates $>5 \mathrm{~Hz}, \mathrm{n}=5 / 6$ were recorded in CA1d/SUBd (all from tg mice) and all had complex spike bursts typical of pyramidal cells (Lapray et al., 2012; Valero et al., 2015). The mean firing rate distribution was typical of pyramidal cells, consisting of a majority of low firing cells and few high firing cells (Fig. 6f) (Mizuseki and Buzsaki, 2013). We found similar firing rates for both genotypes (ntg rest, 0.92 [0.74] Hz, $n=14$ cells; tg rest, 0.73 [2.45] Hz, $n=25$ cells; ntg movement, 0.17 [2.46] Hz, $\mathrm{n}=6$ cells; tg movement 1.05 [3.48] Hz, n=21 cells). Running speeds were also similar across genotype (medians of 6.14 versus $5.11 \mathrm{~cm} / \mathrm{s}$ for $\mathrm{ntg}$ and $\mathrm{tg}$ mice, respectively; $U=165, P=$ $0.229)$.

Interneuron firing rates were typically higher than those of principal cells, lacked complex spikes, and showed a range of bursting activity and rhythmic firing patterns. Mean firing rates were also similar across genotypes (ntg rest, 11.53 [23.82] Hz, n=6 cells; tg rest, 13.17 [11.01] $\mathrm{Hz}, \mathrm{n}=20$ cells; $\mathrm{ntg}$ movement, 18.95 [34.77] Hz, n=4 cells; tg movement 18.6 [12.05] Hz, n=19 cells; $\left.\chi^{2}(3,45)=1.011, P=0.8088\right)$. Overall, the sampled range of firing rates of the recorded principal cells and interneurons in tg mice were similar to ntg littermates and other wild type (wt) mice (Fig. 6g).

Loss of higher firing complex spiking cells in aged mice during goal-directed navigation Spontaneous running and resting, both under freely moving and head-fixed conditions, did not reveal changes in activity of individual neurons across genotypes. Therefore, we investigated whether pTau affected neuronal activity when mice were engaged in a goaldirected navigation task. We trained water-restricted aged head-fixed mice to run on an airsuspended jet ball along a virtual linear track to reach a water reward (with each run counting as a trial). From 9 mice $(22.5 \pm 1.2 \mathrm{mo})$, which had all previously been used in spatial memory tests, 7 successfully ran with a stable gait to the end of the corridor and initiated licking $(n=4 / 4$ $\operatorname{tg}$ and $n=3 / 5 \mathrm{ntg}$ mice). Mice ran $36 \pm 24$ trials per session (1-3 sessions per mouse), ranging from 2 trials (a ntg mouse) to 82 (a tg mouse). For sessions with good coverage ( $>12$ trials), mice ran for similar durations ( $36.4 \pm 10.1 \mathrm{~s}$ for $\mathrm{n}=4 \mathrm{ntg}$ mice (one outlier removed) versus 31.8 $\pm 8.1 \mathrm{~s}$ for $\mathrm{n}=5 \mathrm{tg}$ mice; $\left.t_{(7)}=0.7602, P=0.4719\right)$. During this task we recorded multiple single 
unit activity with acute silicon probes, unilaterally targeting distal CA1d/proximal SUBd (prosubiculum area). We recorded 205 units ( $\mathrm{n}=117$ from $3 \mathrm{tg}$ mice and $\mathrm{n}=88$ from $3 \mathrm{ntg}$ mice), localizing 151 to CA1 and 47 to SUBd (Table S1).

First we compared firing rates of all units that had complex spikes (CS) - putative pyramidal cells. Median rates were significantly different (pooled data, 3.57 [5.65] $\mathrm{Hz}$ for $\mathrm{n}=59$ units from 3 ntg mice versus 1.67 [2.11] $\mathrm{Hz}$ for $\mathrm{n}=91$ units from $3 \mathrm{tg}$ mice; $U=3702, P<0.0001$; Fig. 7a), with unit firing rates having different distributions $(D=0.4193, P<0.0001)$. We also compared firing rates of units that lacked CS - putative interneurons. We found no differences in median firing rates for non-CS units (pooled data, 6.82 [22.11] $\mathrm{Hz}$ for $\mathrm{n}=29$ units from $3 \mathrm{ntg}$ mice versus 10.16 [8.45] Hz for $\mathrm{n}=26$ units from $3 \mathrm{tg}$ mice; $U=342, P=0.5495$; Fig. $7 \mathrm{~b}, \mathrm{~S} 5 \mathrm{~d}$ ) despite different distributions $(D=0.3793, P=0.0260)$. Previous studies have set firing rate thresholds to help separate putative pyramidal cells (assumed to be 'low firing', < $5 \mathrm{~Hz}$ ) from 'high firing' interneurons (Skaggs et al., 1996). When we examined only the 'low firing' CS units (with mean firing rates < $5 \mathrm{~Hz}$ : $54 \%$ of ntg and $88 \%$ of tg CS units, Figs. 7c,d, S5d), we found no difference between genotypes $(1.37$ [2.78] Hz for 32 units from ntg mice versus 1.28 [2.00] Hz for 80 units from tg mice; $U=1386, P=0.4928$ ). When compared with a separate dataset of CA1 CS units obtained from younger mice performing a similar task on the same jet ball (Lasztoczi and Klausberger, 2017), we found no difference between groups for CS units with mean firing rates $<3 \mathrm{~Hz}(0.96$ [1.39] Hz for 161 units from wt mice; 0.61 [1.21] Hz for 22 units from ntg mice; 1.06 [1.74] Hz for 71 units from tg mice; $\chi^{2}(2,251)=2.767, P=0.2515$, Table S1). Since we have identified 'high firing' (> $5 \mathrm{~Hz}$ ) hippocampal CS cells as pyramidal cells (Fig. 6 ), we suggest that higher firing pyramidal cells (CS units), which carry more information than other cells (Mizuseki and Buzsaki, 2013), are preferentially lost in tg mice, leaving the lower firing CS cells.

We also investigated whether the loss of high firing CS units in tg mice affected the relative proportion of place cells (Fig. 7c,d), which represent different locations of the virtual linear track (Chen et al., 2013). Ntg and tg mice had similar proportions of place cells (19.7 \% (16/88 units), $n=3$ ntg mice; $18.2 \%$ (23/117 units), $n=3$ tg mice). Place fields were observed at different locations along the virtual corridor, with some associated with the reward (goal location, Fig. 7c,d). Interestingly, some units showed synchronized firing following reward periods (e.g. units u1586 and u3770, Fig. 7d). These data suggest that place cell mapping is preserved in these aged tg mice.

\section{Preservation of theta rhythmicity in aged mice}

Given that we did not detect any major differences in theta oscillations or other associated spectral components across genotypes (Fig. 5), we hypothesized that the remaining neurons in aged tg mice would retain their theta coupling, despite extensive pTau. Indeed, units from $\operatorname{tg}$ mice were coupled to theta and could become synchronized on individual theta cycles within overlapping place fields (Figs. 7d,e, S5d-f). For CS units, $93 \%$ from ntg mice (n=53/57 units) and $78 \%$ from tg mice ( $\mathrm{n}=58 / 74$ units) were significantly theta coupled (Rayleigh tests, $P>0.05 ;$ Fig. 7c-f). Of the non-coupled CS units from $t g$ mice, 7 were in deep SUBd. There was no difference in theta coupling across genotypes (vector length $r=0.21$ [0.13] for ntg versus $\mathrm{r}=0.19$ [0.16] for tg; $U=1397, P=0.4068$; Fig. 7e). The most strongly coupled CS units had $\mathrm{r}=0.47$ and $\mathrm{r}=0.45$ for $\mathrm{ntg}$ and $\operatorname{tg}$ mice, respectively. We also found no difference in the distributions with respect to theta coupling versus firing rate $(D=0.3595, P=0.0646$; Fig. $7 \mathrm{f})$. For units recorded in prosubiculum, phase distributions were also similar (circular standard 
deviation of phase angles: $53.6^{\circ}$ for ntg mice, $n=23$ units; $54.7^{\circ}$ for tg mice, $n=15$ units; Fig. $7 \mathrm{~g}$ ). Furthermore, for the subsets of theta-coupled CS units with firing rates $<3 \mathrm{~Hz}$, coupling strength was no different from a previously published dataset obtained from younger wt mice (Lasztoczi and Klausberger, 2017) $\left(\mathrm{r}=0.18\right.$ [0.13] for wt mice, $\mathrm{n}=152$ units; $\chi^{2}(2,215)=0.7749, P=$ 0.6807).

For non-CS cells, $94 \%$ from ntg mice (29/31 units) and $78 \%$ from tg mice (25/32 units) were significantly coupled to theta oscillations (Rayleigh tests, $P>0.05$ ), with 7 of the non-coupled non-CS units located within deep SUBd. As with CS units, there were no differences in coupling strength across genotypes $(r=0.22(0.19)$ for $n t g$ versus $0.17(0.16)$ for $\operatorname{tg} ; U=311, P=$ 0.3763; Fig. 7e) or in the distributions of coupling versus firing rate $(D=0.9567, P=0.4577)$. For units recorded in $\mathrm{dCA} 1 / \mathrm{pSUB}$, even the phase distribution (spread) was similar (circular s.d. of phase angles: $57.9^{\circ}$ for $n \operatorname{tg}$ mice, $n=11$ units; $45.8^{\circ}$ for tg mice, $n=16$ units; Fig. S5e,f). In summary, we could detect no differences in theta phase coupling in aged ntg and $\mathrm{tg}$ mice.

\section{Discussion}

We found an age-related progression of pTau in temporal cortical and subcortical areas, consistent with previous reports (Degiorgis et al., 2020; Ising et al., 2019; Schindowski et al., 2006; Van der Jeugd et al., 2013), similar to other Thy1 promoter-driven 4R Tau lines (Gotz et al., 2001; Grueninger et al., 2010; Probst et al., 2000). We further mapped pTau up to 27 mo, finding that deep-layer Wfs1+/CB- hippocampal pyramidal neurons preferentially accumulated pTau, followed by neurodegeneration. Oligodendrocytes also became pTau+ and were associated with pTau + white matter tracts. We suggest the extensive Tau pathology in the hippocampal formation and loss of higher firing cells contributed to specific deficits in short-term familiarity. We did not detect impairments in network oscillations or theta coupling, which likely explains why tests of spatial working and reference memory performance were similar for $\mathrm{tg}$ and $\mathrm{ntg}$ mice.

Mechanisms of pTau spread to oligodendrocytes. The pTau+ coiled bodies we found in oligodendrocytes resemble those in PSP, CBD and Alzheimer's disease (Arima, 1996; Arima et al., 1997; Ferrer, 2018; Nishimura et al., 1995), probably a feature specific to overproduction of $4 \mathrm{R}$ pTau (Shi et al., 2021). They may facilitate pTau propagation in humans, as mice inoculated with pTau from tauopathy patients exhibit spreading via oligodendrocytes (Clavaguera et al., 2013; Ferrer et al., 2019). As Thy1 is neuron-specific (Caroni, 1997), we suggest axonal pTau spreads to oligodendrocytes. Alternatively, Thy1 in oligodendrocytes could be repressed in younger animals or only become activated later; examining aged ThyGFP mice for GFP+ oligodendrocytes may be informative. Oligodendrocytes containing pTau along fiber tracts strongly suggests entry at paranodal septate-like junctions between the axonal membrane and myelin adjacent to the nodes of Ranvier (Poliak and Peles, 2003), which could then spread to the soma (Ikeda et al., 1994). Maturing oligodendrocyte precursor cells may also accumulate pTau (Ferreira et al., 2021); their disruption causes memory impairments (Steadman et al., 2020). Myelinating satellite oligodendrocytes (Lin et al., 2003) are tightly associated with neuronal somata, and are electrically coupled to astrocytes and other oligodendrocytes (Battefeld et al., 2016), so may accumulate pTau from neuronal somata and dendrites. As we have observed coiled bodies close to pTau+ pyramidal neurons, and fewer higher firing pyramidal cells in aged tg mice, disruption of gray matter oligodendrocytes could contribute to the reduction in higher firing activity and affect spike initiation and/or propagation. In mouse models, microglia can secrete phagocytosed human Tau in exosomes, 
and astrocytes are upregulated, facilitating pTau propagation (Degiorgis et al., 2020; Habib et al., 2020; Ising et al., 2019; Perea et al., 2019; Van der Jeugd et al., 2011). Potentially, via similar mechanisms, pTau released into the extracellular space from degenerating neurons could be directly taken up by oligodendrocytes. Transneuronal pTau spread is unlikely as we did not observe Tau tangles in regions innervated by abundant pTau+ SUBd/CA1d pyramidal neurons such as the lateral septum, thalamus or mammillary bodies. However, dorsal prosubiculum projects to the amygdala (Ding et al., 2020), and both regions were enriched in pTau.

Subcortical regions implementing rhythmic cortical neuronal coordination. Theta-coupled bursting GABAergic neurons of the medial septum (MS) project to the temporal cortex (Joshi et al., 2017; Salib et al., 2019; Viney et al., 2018), and MS inactivation reduces cortical theta power and impairs spatial memory (Buzsaki et al., 1983; Jeffery et al., 1995; Leutgeb and Mizumori, 1999; Wang, 2002; Wang et al., 2015). Disruption of MS cholinergic neurons with pTau can also cause memory deficits (Wu et al., 2021) and a reduction of these neurons was reported in THY-Tau22 mice (Belarbi et al., 2011). Selective inactivation of rat anterior or ventral midline thalamic nuclei also results in spatial memory impairments (Frost et al., 2021; Viena et al., 2018); several of these nuclei also contain theta-rhythmic neurons and project to temporal cortical areas. We did not detect pTau+ neurons in the MS or thalamus, which could explain why the distributions of theta coupled neurons, theta peak frequencies, IMFs, and crossfrequency coupling in the heavily pTau dominated CA1d-SUBd regions were broadly similar for both genotypes under our conditions, although we cannot rule out changes in other pTaurich regions (Booth et al., 2016).

Spatial memory. Unimpaired hippocampal neuronal coordination, including SWRs required for memory consolidation, may explain why we observed normal hippocampal-dependent spatial reference and working memory performance. Previous studies reporting that 9-10 mo $\operatorname{tg}$ mice spend longer finding the hidden platform in a Morris water maze also found that they exhibited more thigmotaxis than ntg mice (Van der Jeugd et al., 2011; Van der Jeugd et al., 2013), with deficits emerging as early as 3 mo (Schindowski et al., 2006). Thigmotaxis suggests that mice may additionally use 'non-spatial' strategies. Although the water escape Y-maze that we used minimizes thigmotaxis (Sri et al., 2019), tg mice may have used other strategies to find the goal. Our longitudinal testing of the same mice at different ages may have even acted as an enriched environment, protecting mice from some deficits, as environmental enrichment is known to delay the onset of memory deficits (Berardi et al., 2007). Also, spatial learning can lead to neuroprotective oligodendrogliogenesis (Steadman et al., 2020). Our in vivo recordings were carried out on the behaviorally-tested mice. Naïve aged tg mice show deficits in synaptic transmission (Schindowski et al., 2006), but it remains to be tested if this causes neuronal network changes in vivo.

Reduction in short-term familiarity. We found that $>13$ mo tg mice failed to discriminate novel and other arms of the hippocampus-dependent (Sanderson et al., 2009) spontaneous spatial novelty preference Y-maze, as shown previously in younger mice (Belarbi et al., 2011; Van der Jeugd et al., 2011). This suggests impairment in recognizing familiarity of extramaze spatial cues, which are required for spatial novelty preference (Sanderson et al., 2007). As well as place cells, the dorsal hippocampal formation contains head direction (HD) cells (Frost et al., 2021), which encode orientation. Although tuning of cortical HD cells is unaffected by disruption of theta (Brandon et al., 2013), we predict that a high-firing subset of SUBd HD 
cells are impaired based on a high level of pTau. A reduction in short-term familiarity due to impaired orientation with respect to extramaze cues could also explain why tg mice spent significantly longer in the start arm of the T-maze before initiating forced or choice runs. Interestingly, systemic administration of the group II metabotropic glutamate receptor agonist LY354740 in wt mice can increase the latency of both forced and choice runs but also impairs alternation (Boerner et al., 2017). Lastly, we found that both young and old tg mice naïve to the elevated plus maze spent longer in the open arms. The ventral hippocampus and interconnected BLA also develop early Tau pathology (Degiorgis et al., 2020), and lesions of rat ventral hippocampus alters anxiety-related contextual behavior but not spatial learning (Bannerman et al., 2003; Trivedi and Coover, 2004). Taken together, changes in spatial familiarity may be explained by potential deficits in HD networks in pTau-enriched areas of the hippocampal formation, which will be tested in the future.

Effects of pTau on identified neurons. Our single recorded and labeled neurons lacked pTau, hence we do not know how pTau affects in vivo firing, but in aged tg mice there were fewer higher firing pyramidal cells during goal-directed navigation. To our knowledge, there are no reports on in vivo firing of pTau+ hippocampal neurons. The rTg4510 tauopathy model mice have slower membrane potential oscillations and reduced firing rates, but only one labeled pTau+ neocortical neuron was reported (Menkes-Caspi et al., 2015). In vivo calcium imaging in 6-12 mo rTg4510 mice show diminished activity under anesthesia (Busche et al., 2019). These lower activity levels could be attributed to an actual loss of higher firing cells, shifting the sampled populations towards lower firing cells. Matching pTau content to imaged/recorded neurons is needed to test the effects of pTau on neuronal activity in all models.

Skewed distributions of firing rates are a common feature of the brain, with the high firing minority of cells transmitting the most information, tending to be more highly connected, and able to 'generalize' across different contexts (Buzsáki, 2019; Mizuseki and Buzsaki, 2013). The functional significance is that a loss of higher firing cells would cause previously stronglypotentiated postsynaptic neurons to become less excitable, leading to an overall shift of the firing rate distributions towards a lower median. In experimentally naïve aged tg mice, the shift may be even greater. Chronic high-density recordings would be required to determine whether synaptic plasticity in lower firing cells gradually increases their mean firing rates to 'compensate' for the loss of high intensity inputs. The effect on spatial navigation could be that mice take longer to recognize contexts due to a loss of the 'generalizer' high firing neurons, yet spatial memory is retained due to unimpaired subcortical rhythmic inputs enabling precise spike timing of the remaining place cells, HD cells and other spatiallymodulated neurons. Alzheimer's disease, FTDP, PSP and other tauopathies show Tau pathology in several subcortical areas such as the thalamus and brainstem, which could contribute to the observed memory deficits. Further research into the subcortical contributions to spatial memory performance may provide insight into the drivers of different sporadic tauopathies. 


\section{Figures}

Figure 1. Age-related increase of pTau in THY-Tau22 mice.

Immunoreactivity for AT8 (pTau+) at different ages in the hippocampal formation (A), amygdala (B) and mPFC (C). Widefield epifluorescence, reverse contrast. Asterisks, prosubiculum. (D) Immunoreactivity for pTau (green) in deep cortical layers at 20 mo relative to calbindin (CB, cyan), parvalbumin (PV, magenta) and Purkinje Protein 4 (PCP4, yellow) immunopositive subpopulations. (E) Lack of Tau tangles in the medial septum (MS) in a 22.5 mo tg mouse (case TT21D, female). Neuropil threads mostly within lateral septum (LS). Left, epifluorescence tile showing PV (magenta) and SATB1 (yellow) restricted to the MS. Right, enlarged view, note AT8 (green) mostly in LS. Scale bars $(\mu \mathrm{m})$ : A-C, 200; D, E (left) 500; E (right) 100. Cases in A-C (age group, mouse name, sex): 2-3 mo, TT114A male; 4-6 mo, TV132 male; 8-10 mo, TV134 female and TV143 male; 13-16 mo, TT21E female; >18 mo, TT33G female. Abbreviations: months, m; CA1d, dorsal CA1; SUBd, dorsal subiculum; DG, dentate gyrus; $\mathrm{LV}$, lateral ventricle; BLA; basolateral amygdala; M2, secondary motor cortex; PrL, prelimbic cortex. 
bioRxiv preprint doi: https://doi.org/10.1101/2021.1124 469849; this version posted November 25, 2021. The copyright holder for this

preprint (which was not certified by peer review) is the author/funder, who has granted bioRxiv a license to display the preprint in perpetuity. It is made available under aCC-BY-NC-ND 4.0 International license.
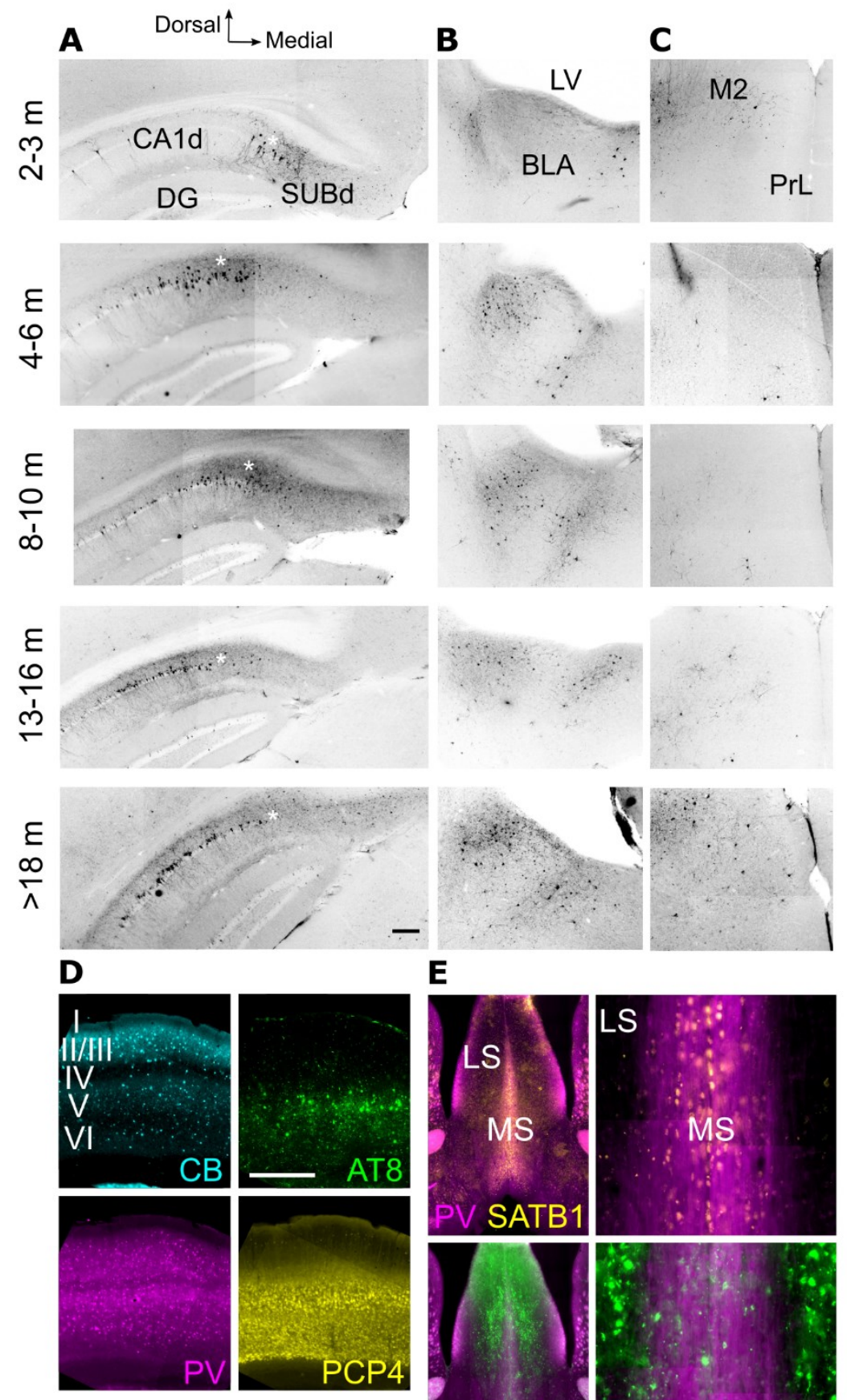

\section{$\mathbf{E}$}
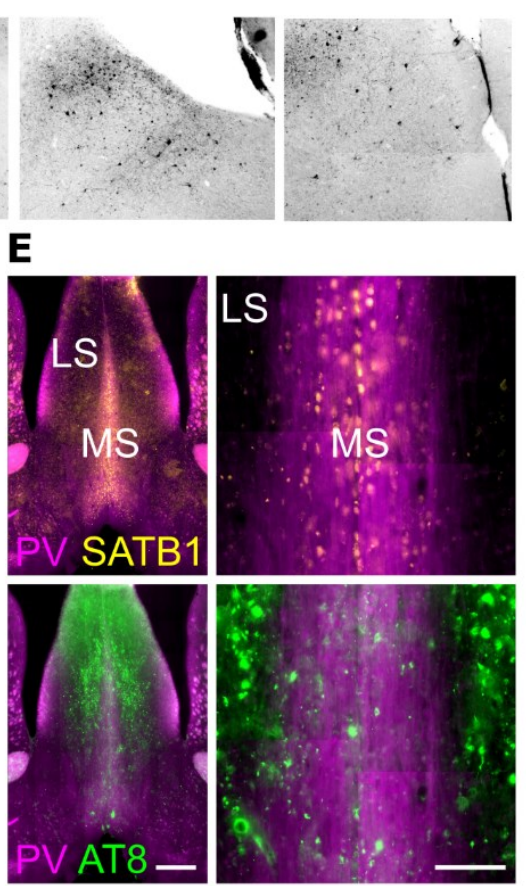
Figure 2. Preferential accumulation of pTau in deep-layer CA1 pyramidal cells.

(A) Neurons immunoreactive for pTau (AT8, green, arrows) show nuclear immunoreactivity for CTIP2 (magenta) in CA1d SP. Widefield epifluorescence, case TV136. (B) A pTau+ neuron (asterisk) in distal CA1d SP immunopositive for SATB2 (cyan). Note PV+ basket terminals around somata (magenta). Confocal single optical section $(0.43 \mu \mathrm{m}$ thick), case TT21D. (C) Weak Wfs1 immunoreactivity (cyan) in pTau+ distal CA1d neurons (AT8, green, asterisks). Confocal single optical section (1 $\mu \mathrm{m}$ thick), case TV133. (D) Cells in CA1d SP immunopositive for pTau (AT8, green). Calbindin (CB), cyan. Widefield epifluorescence. Bottom, detail from above showing lack of detectable CB or PV (magenta) immunoreactivity in pTau+ neurons within deep SP (arrows). (E) Electron micrograph of a proximal SUBd pyramidal neuron dendrite containing AT8-positive filaments (gold-silver particles). Case TT33G (21 mo female). (F, G) Immunoreactivity of SATB2 (cyan) and AT8 (green) in CA1d of 22 mo ntg and $\operatorname{tg}$ mice. Insets, enlarged views of SP. Widefield epifluorescence. $(\mathrm{H})$ Distribution chart of SATB2+ nuclei counts in CA1d ( $\mathrm{n}=3$ mice/genotype). Alveus, Alv; stratum oriens, SO; stratum radiatum, SR; stratum lacunosum moleculare, SLM. Scale bars $(\mu \mathrm{m})$ : A, C 20; B 10; D (top), F, G 100; D (bottom) 50; E 0.5. 
bioRxiv preprint doi: https://doi.org/10.1101/2021.11.24.469849; this version posted November 25, 2021. The copyright holder for this

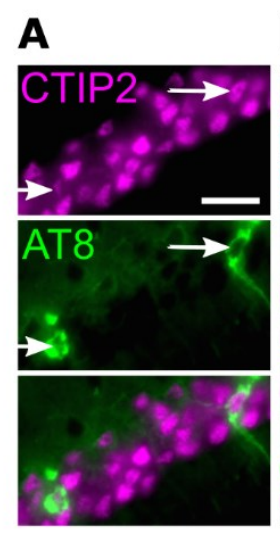

D

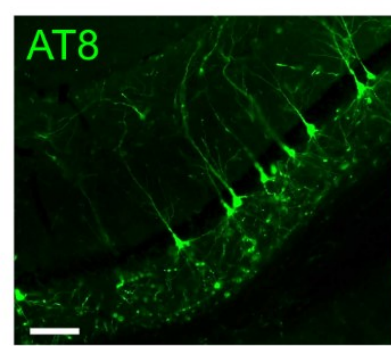

B

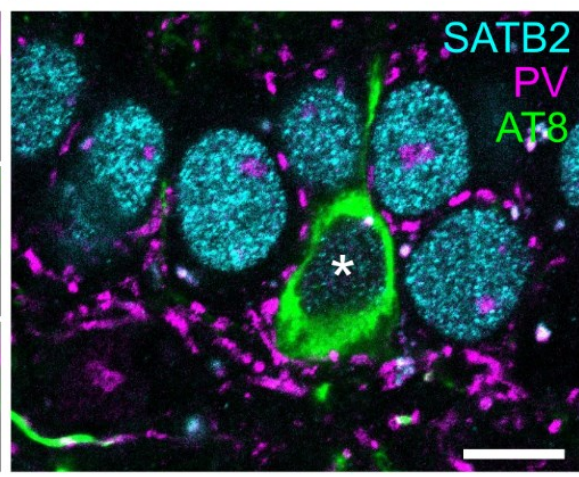

C

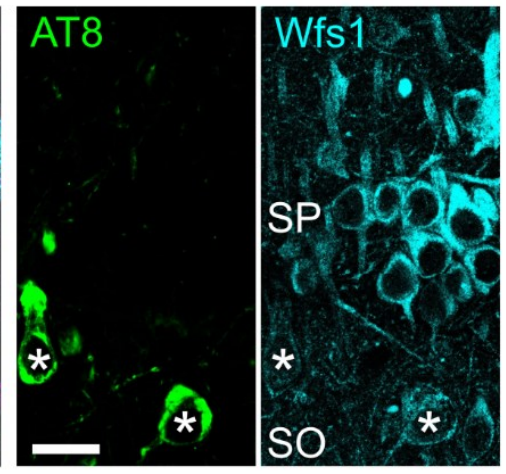

$\mathbf{E}$

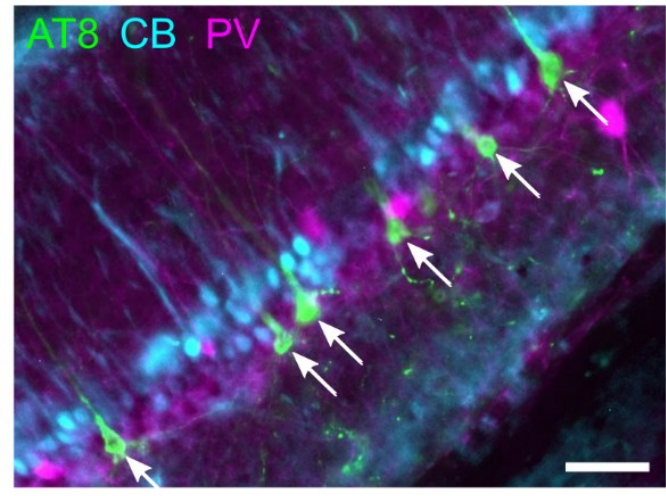

$\mathbf{F}$

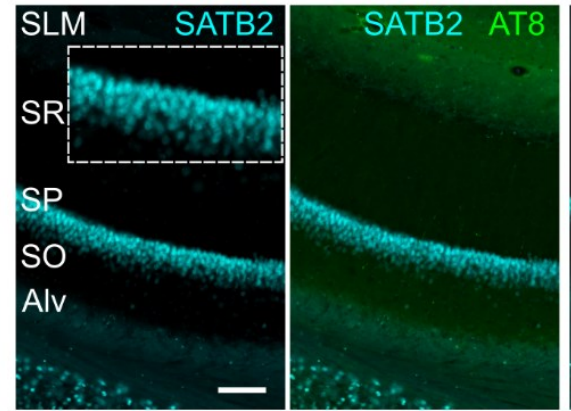

G

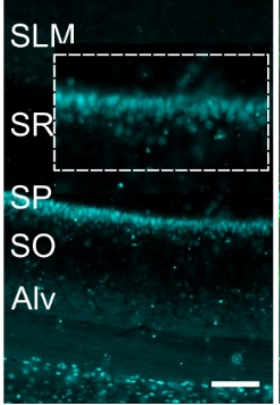

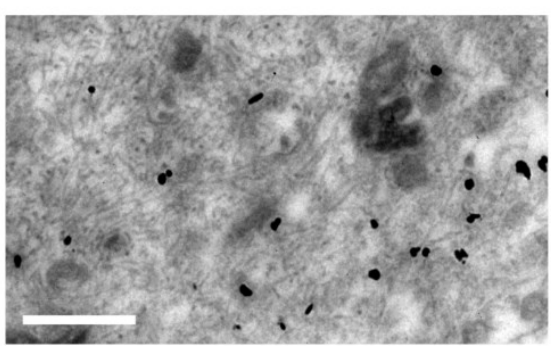

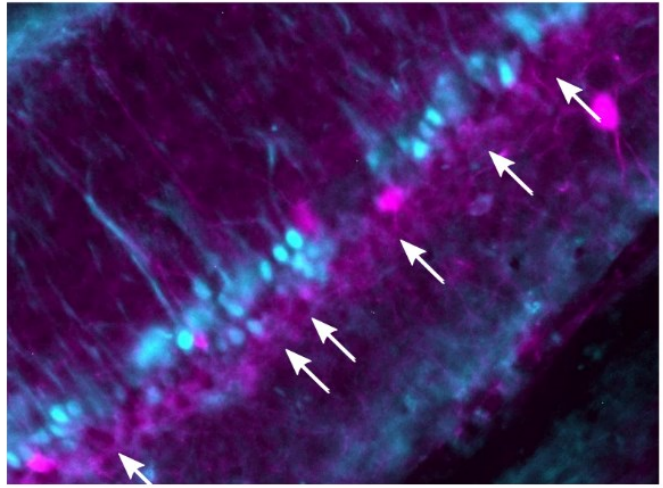

$\mathrm{Tg}$

H
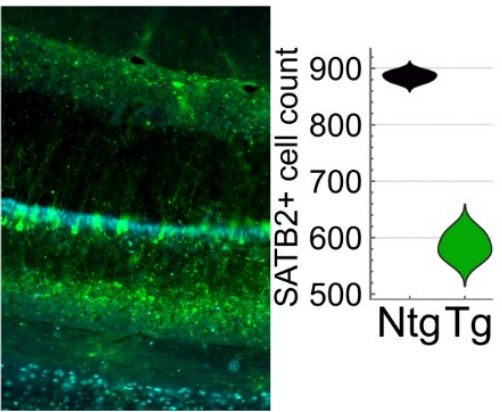
bioRxiv preprint doi: https://doi. org/10.1101/2021.11.24.469849 this version posted November 25, 2021. The copyright holder for this preprint (which was not certified by peer review) is the author/funder, who has granted bioRxiv a license to display the preprint in perpetuity. It is made available under aCC-BY-NC-ND 4.0 International license.

Figure 3. Accumulation of pTau in oligodendrocytes.

(A) Olig2 (magenta) and pTau (AT8, green) in a brain section from a 20 mo tg mouse (widefield epifluorescence). Note high density of pTau in fimbria (fi). (B) Enlarged view of boxed region from (A) of the fornix ( $f x$ ), showing neuropil threads (axons) and coiled bodies. (C) Nuclear immunoreactivity for Olig2 (magenta, asterisks) surrounded by coiled bodies (green, AT8). Right, enlarged view of 'microcoils' near an Olig2+ nucleus (boxed region, middle panel). (D) Coiled bodies colocalizing with Olig2+ nuclei in the fimbria. (E) AT8positive filaments (gold-silver particles) in the cytoplasm of an oligodendrocyte in proximal SUBd next to an Olig2-immunolabeled nucleus (n) (peroxidase labeling). Right, higher magnification. Abbreviations: Str, dorsal striatum; cc, corpus callosum; st, stria terminalis; AT, anterior thalamus. Scale bars ( $\mu \mathrm{m})$ : (A) 500; (B) 100; (C) 10, 10, 2; (D) 10; (E) 0.5. Confocal maximum intensity projection thickness ( $\mu \mathrm{m})$ : (C) 4, 9.6, 2.4; (D) 4 .

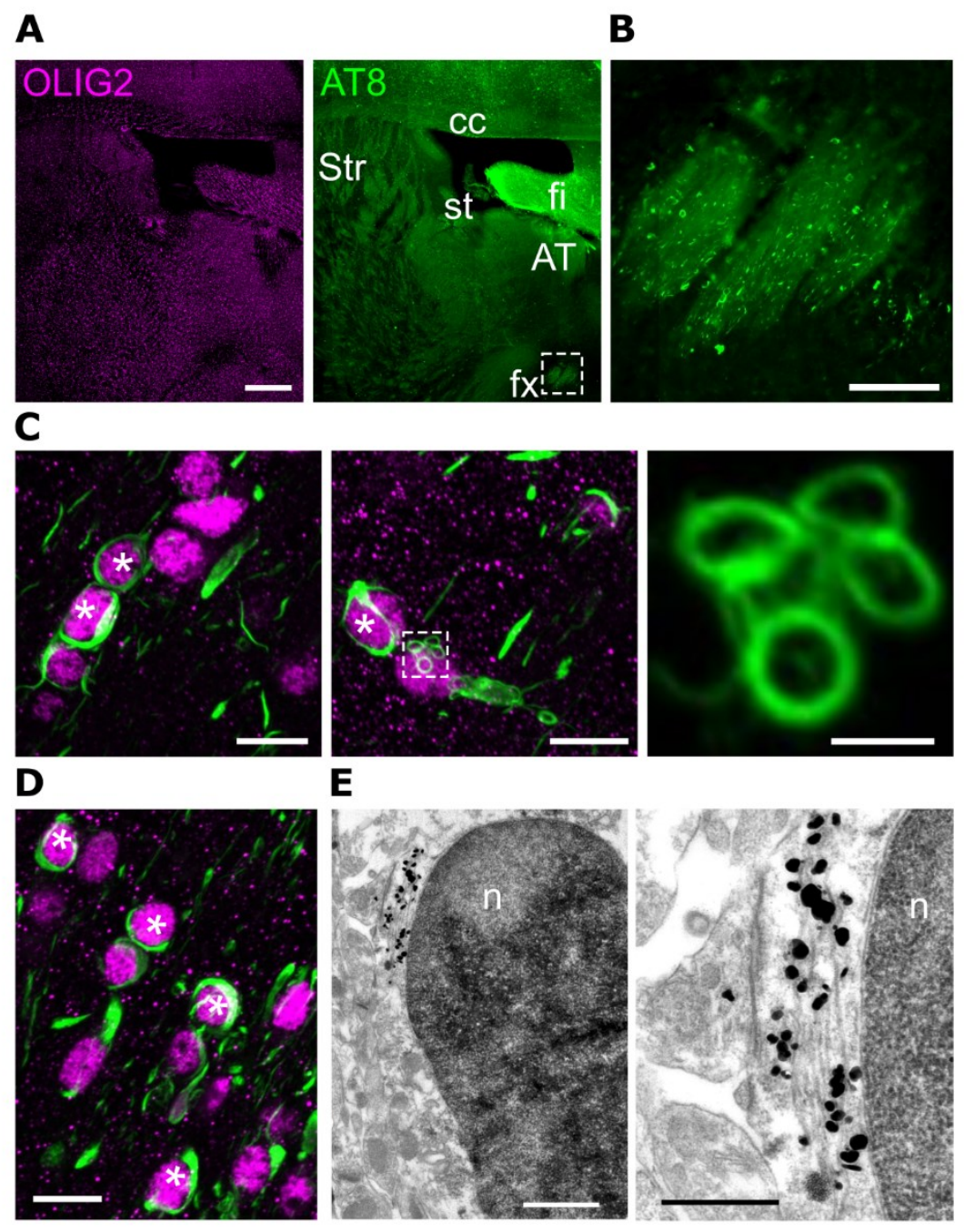


Figure 4. Selective impairments in spatial novelty preference.

(A) Short-term spatial novelty preference Y-maze test. Left, schematic (extra-maze cues not shown). Novel arm is blocked off for exposure phase and block removed for test phase (magenta bar). Middle, total distance traveled during test phase. Right, distribution chart for discrimination ratio; dashed line, no discrimination (0.5, chance). (B) Water escape Y-maze task. Left, schematic: two possible start arms and a goal arm containing a hidden platform submerged in opaque water. Middle, mean values for \% correct over time (blocks). Error bars, standard error. Right, distribution chart for probe test. Dashed lines, chance. (C) Nonmatching to place T-maze task. Left, schematic: start arm and rewarded goal arms. In choice run, block (magenta bar) is removed. Mean alteration scores over time (blocks) for each age. Error bands, standard error. Dashed line, chance. (D) Left, distribution chart of mean choice run delay times (ntg, black; tg, green) during training in T-maze at 4, 7, and 12 mo. Right, mean and standard error across blocks. See Fig. S4b for forced run delay times. (E) Elevated plus-maze with open and closed arms (left). Distribution charts for \% time in open arms (middle) and number of arm entries (right). Asterisks in A, D, E: significant differences. Abbreviations: $\mathrm{m}$, months; NTG, non-transgenic; TG, transgenic mice. 
A Other
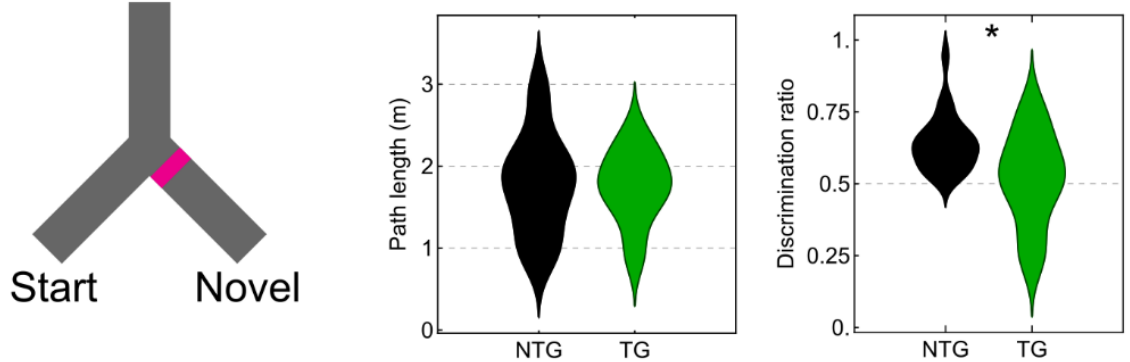

B Start 1

Start 2

Goal
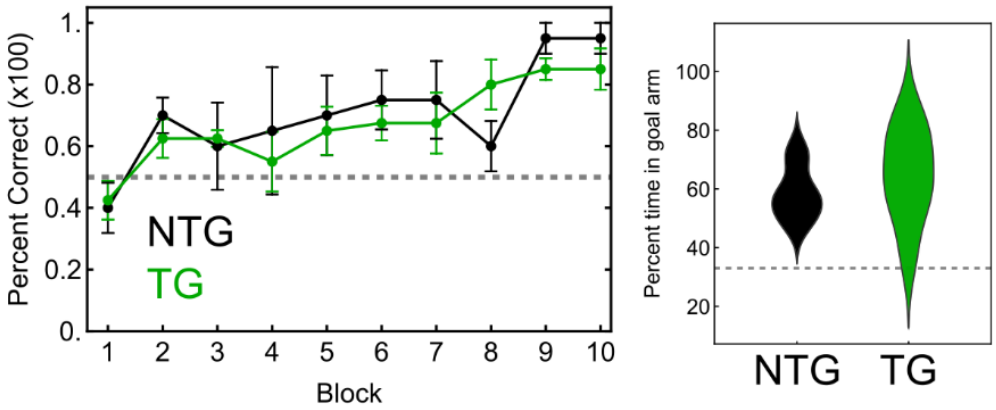

C
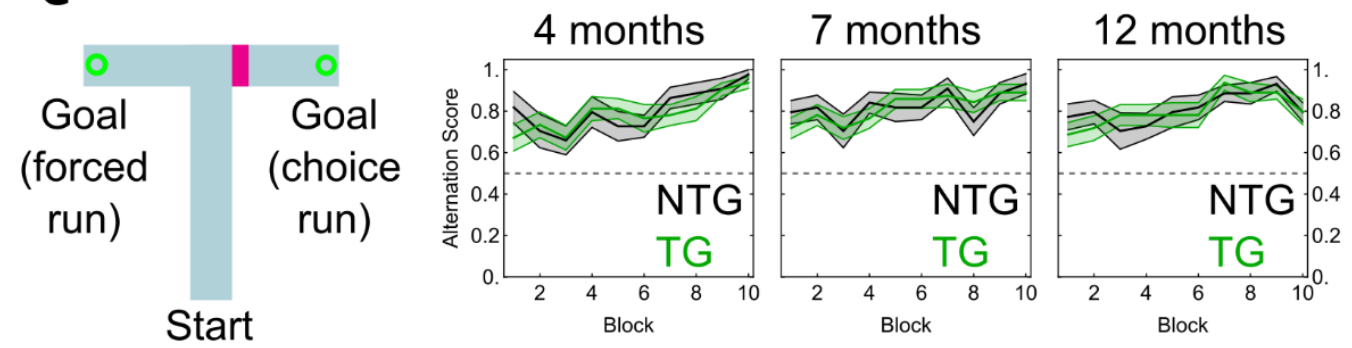

D
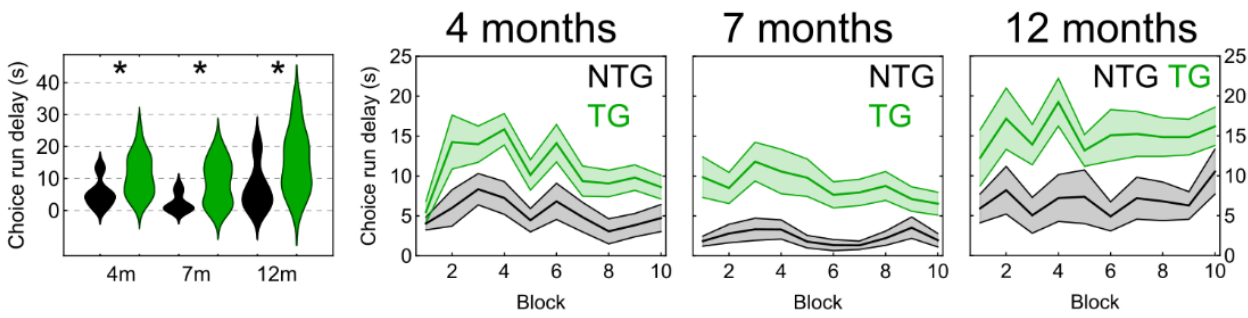

E
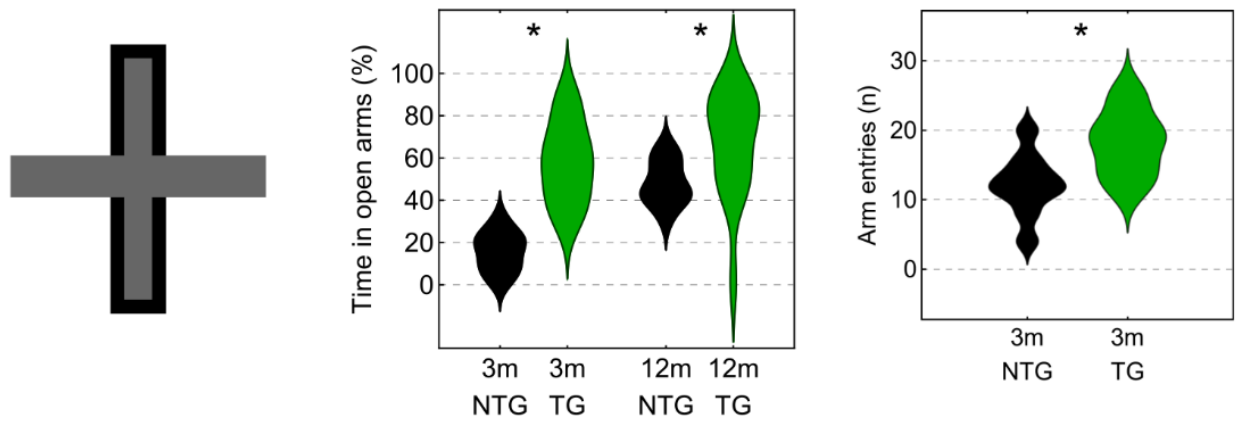
Figure 5. Similar hippocampal network oscillations in tg and ntg mice.

(A) LFP during movement for 18 mo littermates (ntg mouse, black, case TV140; tg mouse, green, case TV139). (B) Distribution chart of peak theta frequencies for two speed bins during spontaneous movement on a running disc, and during navigation in virtual reality (VR). Asterisk, significant difference. (C) Empirical mode decomposition of glass electrode LFP in CA1d SP during movement. Theta (IMF6), slow-gamma (IMF4), mid-gamma (IMF3) and fastgamma (IMF2) oscillations; IMF7 likely corresponds to 'delta' and IMF5 to 'beta'. (D) Probability density functions (PDF) of instantaneous frequency for the 7 IMFs. Top, ntg mouse (23 mo, case TV147). Bottom, tg mouse (18 mo, case TV139). Note similar distributions and spectral peaks. (E) Left, unfiltered wideband LFP from a 13 mo tg mouse (case TV136) with IMF6 (purple, theta) and IMF3 (orange, mid-gamma). Black curve, instantaneous amplitude for IMF3; note higher amplitude near peaks of some theta cycles (asterisks). Right, comodulogram of a $30 \mathrm{~s}$ movement epoch binned for IMF6 (theta) phase. Note phase amplitude coupling for mid-gamma (IMF3) around peak-to-descending theta phase. Theta frequency also modulated by phase. Black curve, sinusoidal schematic theta cycle. Color bar: green, maximum; white, minimum amplitude.

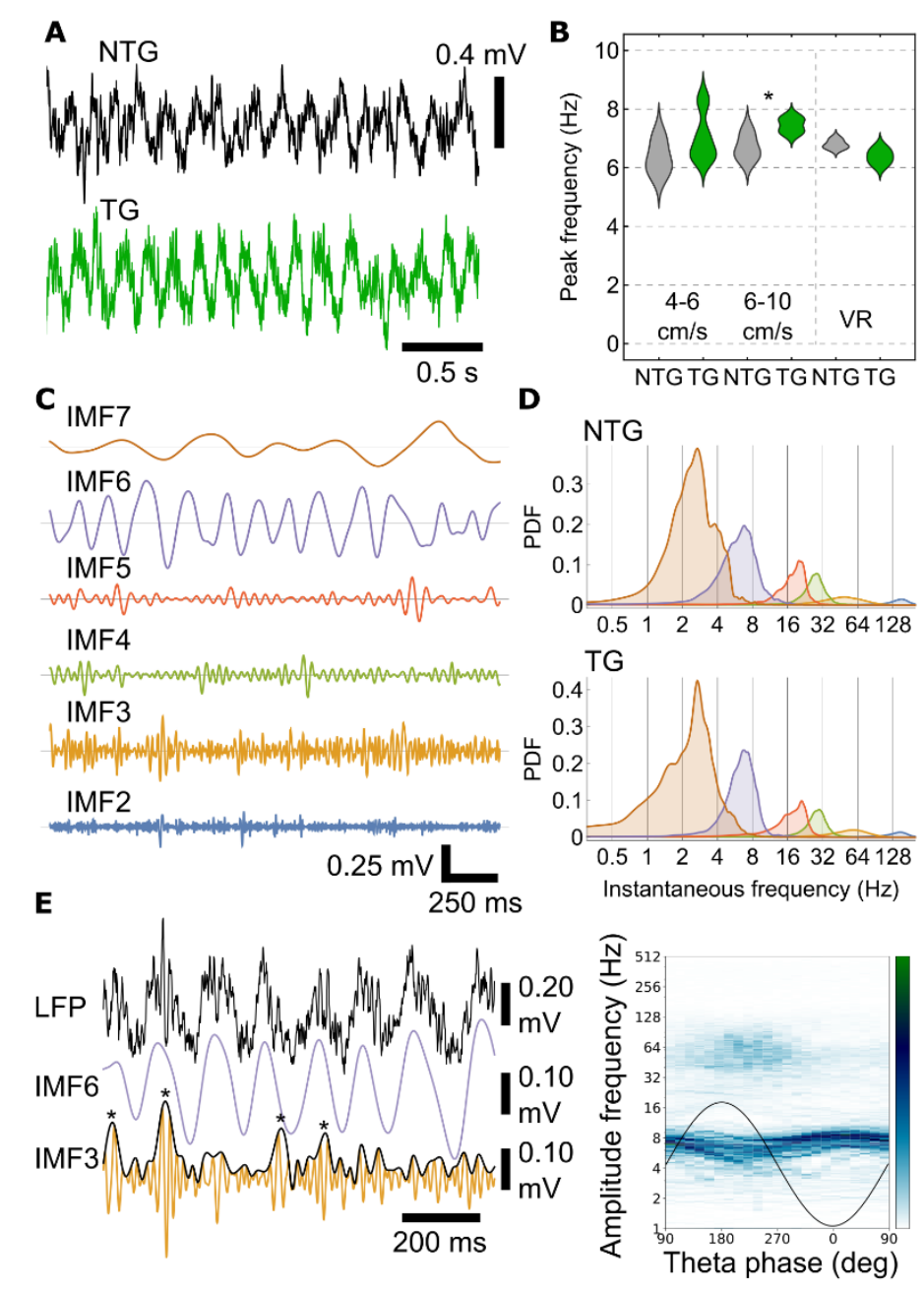


Figure 6. Typical firing patterns of identified hippocampal neurons recorded in awake mice. (A) Glass electrode extracellular recordings of pyramidal neurons in freely moving mice. Top, LFP in prosubiculum and associated band-pass filtered spikes from cell TV140h during spontaneous rest and exploration (18 mo ntg). Bottom, LFP recorded in CA1d (tungsten wire, contralateral) and spikes from cell TV134i (10 mo tg). Accel., acceleration. Asterisks, higher amplitude theta during movement. (B) Identified cell TV140h from A in prosubiculum (neurobiotin, red). Cell lacked detectable immunoreactivity for calbindin (CB, cyan) but was immunopositive for CTIP2 (inset, green). Widefield epifluorescence. (C) Glass electrode recordings in head-fixed tg mice. Wideband LFP of large irregular activity and spikes during rest from cells TV142t (top, $18 \mathrm{mo}$ ) and BS04a (bottom, $13 \mathrm{mo}$ ). Right, complex spikes at higher time resolution (asterisks). (D) Identified CA1 pyramidal cell TV142t (neurobiotin, red) from C lacks pTau (green). Widefield epifluorescence. (E) Identified CA1 pyramidal cell BS04a (neurobiotin, red) from C lacks pTau (green) and calbindin (cyan, asterisk) but is CTIP2+ (green, asterisk). Confocal maximum intensity z-projections (top, $48.5 \mu \mathrm{m}$ thick; bottom, 9.25 $\mu \mathrm{m}$ thick). (F) Distribution charts of mean firing rates during rest and movement. Top, pyramidal neurons (ntg, black; tg, green), bottom, interneurons (ntg, gray; tg, light green). (G) Firing rates for movement versus rest. Right, detail of lower firing cells from left. Color coded as in F. Scale bars ( $\mu \mathrm{m})$ : (B, D left) 100; (D right) 50; (E top) 30; (E bottom) 15. 
bioRxiv preprint doi: https://doi.org/10.1101/2021.11.24.469849; this version posted November 25, 2021. The copyright holder for this
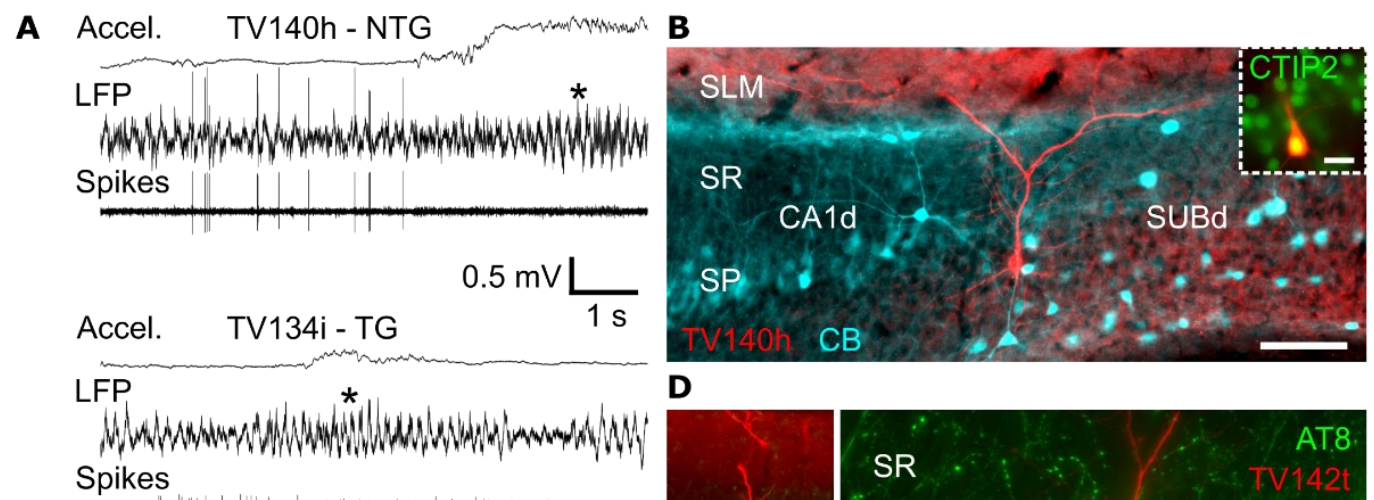

\section{D}

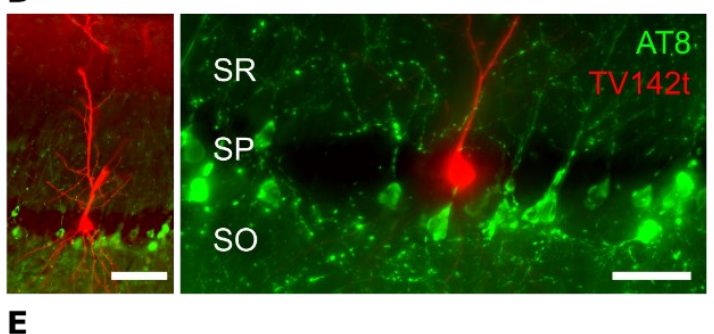

C
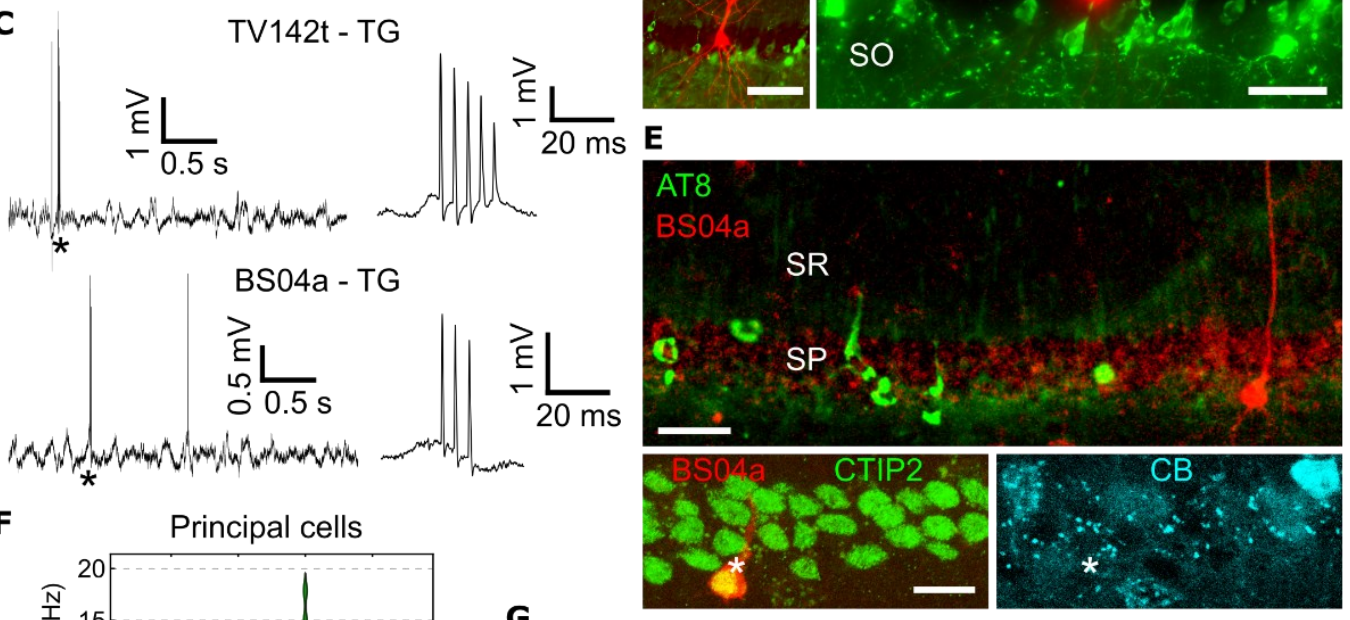

$\mathbf{F}$
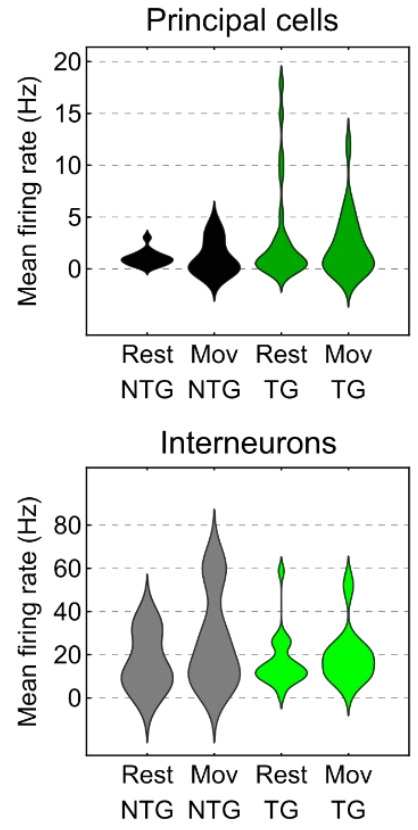

G
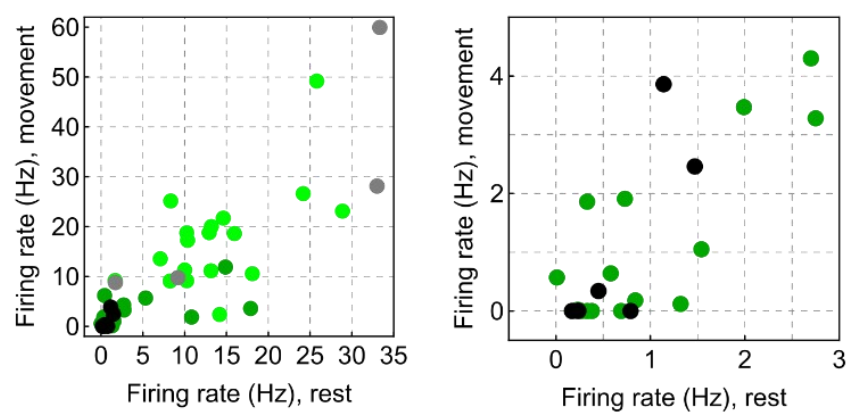

- Interneuron (TG)

- Interneuron (NTG)

- Principal cell (TG)

- Principal cell (NTG) 
Figure 7. Loss of higher firing complex spiking cells but normal theta coupling in aged tg mice. Distribution charts of complex spiking (CS) units (A) and non-CS units (B) per mouse (left), and for pooled data (middle). Right, PDF for pooled data. Red autocorrelograms feature units from a tg mouse (case TO124, 23 mo). Asterisk, significant difference. (C) Two place cells from case TO124: unit (u) 4017 most active towards start of virtual linear track, whereas u3770 most active following reward $(\Delta)$ at end of track. Color bars, 1 to $99 \%$ of linearized firing rate (blue min., red max.). Insets, theta phase histogram $\left(20^{\circ}\right.$ bins; $180^{\circ}$ corresponds to peak shown by red sinusoid). (D) Spike trains from 6 units (case TO124), non-CS units in bold. Note u1586 and u3770 are rhythmically synchronized after reward. 'Teleport', re-initialization of linear track (new trial). Also note coupling to LFP theta cycles, and spikes corresponding to place field of u4017 from C. (E) Distribution chart of coupling strength (vector length, $r$ ) for all units. (F) Firing rate during theta versus vector length for individual units. Black, ntg mice; green, $\operatorname{tg}$ mice. 

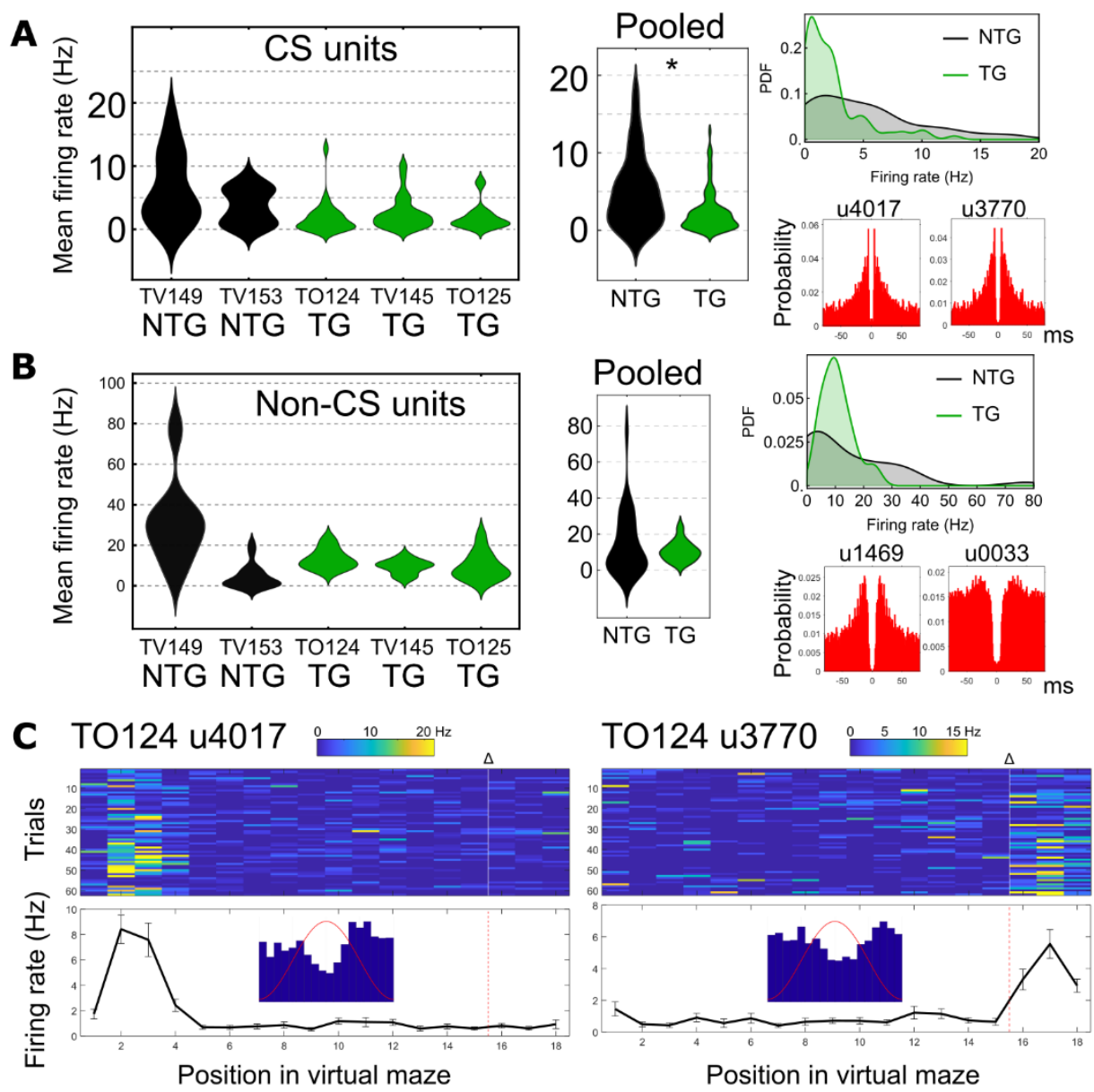

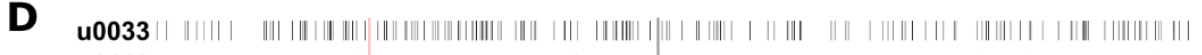
u1469

u3676

u4017

u1586

u3770

|| || || || || || || || | || ||

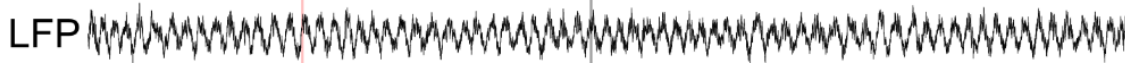

Reward $\quad$ Teleport $1 \mathrm{~s} \longrightarrow 0.5 \mathrm{mV}$
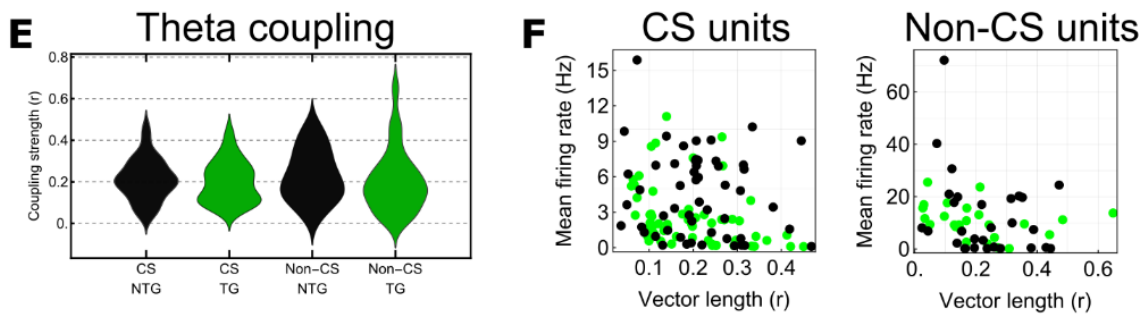


\section{Acknowledgements}

This study was supported by the Medical Research Council (MR/R011567/1), Alzheimer's Society (522 AS-PhD-19a-010), Wellcome Trust (108726/Z/15/Z), Erasmus+, and the Nuffield Benefaction for Medicine and the Wellcome Institutional Strategic Support Fund (0007268). We thank Luc Buée and INSERM for kindly providing THY-Tau22 mice, Vitor Lopes dos Santos for advice on empirical mode decomposition, Balint Lasztoczi for silicon probe recording data from wild type mice, Emily Hunter for assistance with histology, and Sawa Horie and Katalin Lengyel for providing training to B.S. for electron microscopy. We thank Alex Jeans for commenting on an earlier version of the manuscript.

\section{Author contributions}

Conceptualization: T.J.V., B.S., A.T.O., K.H., J.S., D.B., P.S.; Methodology: T.J.V., B.S., A.T.O., K.H., J.S., D.B., P.S.; Investigation: T.J.V., B.S., A.T.O., K.H., J.S., D.B., P.S.; Writing - Original Draft: T.J.V.; Writing - Review \& Editing: T.J.V., B.S., A.T.O., K.H., J.S., D.B., P.S.; Funding Acquisition: T.J.V., P.S.; Supervision: T.J.V., A.T.O., P.S.

\section{Declaration of interests}

The authors declare no competing interests.

\section{Materials and Methods}

\section{RESOURCE AVAILABILITY}

\section{Lead Contact}

Further information and requests for resources and reagents should be directed to and will be fulfilled by the lead contact, Tim Viney (tim.viney@pharm.ox.ac.uk).

Materials Availability

This study did not generate new unique reagents.

Data and code availability

- Raw imaging and electrophysiological data reported in this paper will be shared by the lead contact upon request.

- All original code will be made publicly available as of the date of publication.

- Any additional information required to reanalyze the data reported in this paper is available from the lead contact upon request.

\section{EXPERIMENTAL MODEL AND SUBJECT DETAILS}

All animal procedures were approved by the local Animal Welfare and Ethical Review Body under approved personal and project licenses in accordance with the Animals (Scientific Procedures) Act, 1986 (UK) and associated regulations. A total of 90 mice were used in this study (50\% were female), comprising 3 C57Bl6j mice (wt), 46 heterozygous THY-Tau 22 mice (tg), and 41 non-transgenic littermates (ntg). The THY-Tau22 transgenic mouse line was created by the Buée lab, with Thy1.2 driving expression of human MAPT with G272V and P301S mutations (Schindowski et al., 2006). We bred mice on a C57Bl6j background, as in the original publication. We defined 'aged mice' as $>18$ mo (Hamieh et al., 2021). The oldest was $27 \mathrm{~m} 18 \mathrm{~d}$ at the scientific endpoint (case TO117, tg female, glass electrode recordings; see below). Almost all aged mice reached their scientific end point (100\% of female ntg mice 
$(\mathrm{n}=16 / 16), 91 \%$ of female tg mice $(\mathrm{n}=19 / 22), 94 \%$ of male $\mathrm{ntg}$ mice $(\mathrm{n}=17 / 18), 100 \%$ of male $\operatorname{tg}$ mice $(n=13 / 13))$.

Body weight was routinely monitored. Young male tg mice had reduced weight compared to ntg mice $\left(\sim 8 \%\right.$ difference; $31.6 \pm 2.3 \mathrm{~g}$ ntg mice $(\mathrm{n}=11)$ and $26.8 \pm 0.45 \mathrm{~g} \operatorname{tg}$ mice $(\mathrm{n}=5) ; \mathrm{F}_{(1,14)}=$ 20.3, $\mathrm{p}<0.001$, one-way ANOVA; 3-5 mo; Fig. S1d), confirming previously published data (Schindowski et al., 2006). Ageing tg mice also had reduced body weight (38.3 $\pm 3.2 \mathrm{~g}$ male $\mathrm{ntg}(\mathrm{n}=7), 28.8 \pm 2.6 \mathrm{~g}$ male $\mathrm{tg}(\mathrm{n}=7), 37.1 \pm 0.77 \mathrm{~g}$ female $\mathrm{ntg}(\mathrm{n}=4), 28 \pm 1.4 \mathrm{~g}$ female $\mathrm{tg}(\mathrm{n}=6)$; two-way ANOVA $F_{(1,20)}=67.4, P<0.001$ for genotype, $P=0.7680$ for sex, $P=0.7467$ for genotype-sex interaction; $18-21$ mo; Fig. S1d). In 22-25 mo mice, there was a significant weight difference between sexes $(37.5 \pm 2.5 \mathrm{~g}$ male $\mathrm{ntg}(\mathrm{n}=6), 27.3 \pm 1.5 \mathrm{~g}$ male $\operatorname{tg}(\mathrm{n}=6), 33.1 \pm 6.9 \mathrm{~g}$ female $n \operatorname{tg}(\mathrm{n}=8), 24.8 \pm 2.9 \mathrm{~h}$ female $\operatorname{tg}(\mathrm{n}=11) ; F_{(1,27)}=38.1, P<0.001$ for genotype, $P=0.0323$ for sex, $P=0.5460$ for genotype-sex interaction; Fig. S1d).

Of the 55 mice that underwent behavioral testing, 17 were subsequently implanted for electrophysiological recordings. A further 17 mice not tested behaviorally were also used for electrophysiological recordings. Most mice were perfuse-fixed at their scientific endpoint, with 10/90 mice used only for histology. The remaining 8 mice were monitored for weight only and not used in procedures. Animals were maintained in individually ventilated cages with their littermates on a 12/12 h light-dark cycle (lights on at 07:00) and all behavioral tests were carried out during the daytime. Implanted mice were also grouped housed wherever possible. Room temperature was maintained at $21^{\circ} \mathrm{C}$ and humidity was between $50-60 \%$. Running wheels were placed in the cages of mice undergoing habituation/training to the jet ball (see below). All mice were fed on a standard RM3 diet (pellets, product 801700, Special Diets Services). Each animal was assigned a name (two letters followed by a code, e.g. TT21D, TV140), glass electrode recorded cells were assigned a lower case letter (e.g. TV140h, Fig. 6a), and units isolated from silicon probes were assigned a code (e.g. TO124 u4017, Fig. 7c).

\section{METHOD DETAILS}

Electrophysiological recordings, behavioral tests, and cell counts were made blind to genotype.

\section{Surgical procedures.}

Mice were anesthetized with isoflurane and the scalp was clipped. After subcutaneous injection of Buprenorphine $(0.1 \mathrm{mg} / \mathrm{kg}$ dose, Vetergesic, Ceva), mice were fixed to a stereotaxic frame (Kopf Instruments) via ear bars and a jaw bar and maintained with 1-3 \% (v/v) isoflurane on a homeothermic blanket (Harvard Apparatus). Ocular lubricant was applied to the eyes, and Bupivacaine (Marcaine, Aspen) was injected into the scalp. Under aseptic conditions, an incision was made along the scalp to expose the skull. Two M1 screws (Precision Technology Supplies) were fixed into the skull above the cerebellum, with one or both used as electrical reference. Another screw was fixed $\sim 1.50 \mathrm{~mm}$ anterior of the bregma. After scoring the skull and applying a thin layer of cyanoacrylate super glue, a machined glass-reinforced plastic D-shaped head plate (custom made at the Department of Physics, Oxford University) was positioned over the screws and Refobacin bone cement (Zimmer Biomet) was used to secure the head plate and screws to the skull. A $0.7 \mathrm{~g}$ head plate was used for head-fixed and freely moving mice, and a slightly longer $1.1 \mathrm{~g}$ head plate was used for jet ball experiments. Mice that failed to learn for jet ball experiments could be used in head-fixed recordings. Similarly, if freely moving mouse recordings failed, head-fixed recordings could be carried out instead. For the experiments involving freely moving mice, a 7 stranded 
PerFluoroAlkoxy-coated steel wire (0.002 inch thickness, A-M Systems) was stereotaxically inserted into CA1d to target stratum pyramidale $(-2.30 \mathrm{~mm}$ antero-posterior $(\mathrm{AP})$ and 1.50 $\mathrm{mm}$ medio-lateral (ML) from bregma, $1 \mathrm{~mm}$ below the dura mater) and secured with bone cement and/or blue-light curing dental cement (Tetric EvoFlow, Ivoclar Vivadent). A custommade stainless steel NanoMotor holder (Department of Pharmacology, Oxford University) was secured with bone cement to one side of the head plate. A headstage connector (a double row of pins) was also secured to the head plate, and the tungsten wire and reference were soldered to specific pins of the connector. Mice were administered a subcutaneous injection of $0.5 \mathrm{ml} 5 \%(\mathrm{w} / \mathrm{v})$ glucose in saline (Aqupharm 3, Animalcare) peri-operatively. Craniotomy sites were as follows (mm from bregma): -2.90 AP, 1.75 ML (distal CA1d / proximal SUBd, also known as prosubiculum (Ding et al., 2020), for the majority of mice); -3.20 AP, 1.90 ML (SUBd); -2.50 AP, 1.70 ML, $10^{\circ}$ posterio-anterior angle (CA1d). In some mice, craniotomies were performed during the first surgery immediately after head plate implantation. In all others (including all mice for jet ball experiments), craniotomy sites were marked by partially drilling into the skull, silicon (Smooth-On) was used to cover the skull inside the head plate, and mice were left to recover in a home cage over a heated blanket. After habituation/training (below), a second brief surgery was carried out, with the same anesthesia regime as above. Craniotomies were performed at the marked sites, and the dura was removed with a bent 27 gauge needle. Silicon was used to protect craniotomy sites and mice were left to recover in a home cage over a heated blanket. Electrophysiology experiments were initiated the following day.

\section{Electrophysiology.}

Glass electrode recordings in head-fixed mice. Implanted mice were habituated to head-fixation using a custom-made stainless steel block (Department of Physics, Oxford University), secured to a heavy-duty frame (model 1430, Kopf Instruments). Mice could spontaneously run and rest on a $30 \mathrm{~cm}$ diameter plastic Frisbee ('running disc') covered with paper roll. On recording days, the silicon was removed and replaced with sterile saline. Two separate glass electrodes filled with $3 \%$ neurobiotin (w/v) in $0.5 \mathrm{M} \mathrm{NaCl}(8-18 \mathrm{M} \Omega)$ were advanced into the craniotomy sites using IVM-1000 micromanipulators (Scientifica Ltd) to reach the hippocampus/subiculum bilaterally. Signals were amplified x1000 (ELC-01MX, BF-48DGX and DPA-2FS modules; npi Electronic $\mathrm{GmbH}$, Tamm, Germany). Both wide-band ( $0.3 \mathrm{~Hz}$ to 8 $\mathrm{kHz}$ ) and band-pass-filtered (action potentials, $0.8-8 \mathrm{kHz}$ ) signals were acquired in parallel for each glass electrode and digitized at $20 \mathrm{kHz}$ (Power1401; Cambridge Electronic Design Ltd, Cambridge, UK). HumBugs (Digitimer Ltd) were used to remove $50 \mathrm{~Hz}$ noise. A video camera was used to monitor behavior. Speed was measured using a rotary encoder (HEDM5500\#B13, Avago Technologies) attached to the underside of the Frisbee. Data were recorded using Spike2 software (Cambridge Electronic Design). Local field potential (LFP) measurements and extracellular recordings of single neurons were made bilaterally during spontaneous movement and rest periods. Cells of interest were juxtacellularly labeled with $200 \mathrm{~ms}$ positive current pulses, followed by a recovery period of at least $4 \mathrm{~h}$.

Glass electrode recordings in freely moving mice. Mice were head-fixed as above and the craniotomy site was exposed (the contralateral site had the implanted tungsten wire). A custom-made piezo-electric NanoMotor (Kleindiek Nanotechnik and npi Electronic) was secured in the holder on the head plate and a miniature preamplifier/headstage (custommade by npi Electronic) was attached to the headstage connector. A glass electrode containing $3 \%$ neurobiotin in $0.5 \mathrm{M} \mathrm{NaCl}$ was attached to the NanoMotor and lowered into the brain. 
The mouse was released from head restraint and placed in a $50 \mathrm{~cm}^{2}$ open field with $30 \mathrm{~cm}$ high walls. Occasionally objects were added to the environment. Acceleration was measured with a built-in accelerometer and motion was tracked with a video camera and integrated LEDs on the headstage or by body-motion capture. Extracellular single neuron recordings and LFP measurements were made as for head-fixed mice, followed by juxtacellular labeling. Mice were returned to head-fixation in order to remove the NanoMotor and miniature headstage or continue head-fixed recordings as above.

Jet ball recordings. Mice were first handled for at least $2 \mathrm{~d}$ then ad libitum access to water was removed to initiate water restriction. Mice were gradually habituated to head-fixation over an air-suspended Styrofoam jet ball (part of a virtual reality (VR) setup, PhenoSys GmbH, Berlin, Germany). Mice were trained to run on the jet ball to advance a virtual linear track (projected in a dome). Once they reached the end, licking would release a $10 \mu \mathrm{l}$ water reward. Animals were teleported to the start of the virtual corridor to initiate the next run. Running followed by licking at the reward location was defined as goal-directed navigation. Each animal was trained twice daily for $\sim 30 \mathrm{~min}$ for 8-10 d. Throughout the training days, the length of the virtual corridor was increased stepwise to make sure animals were motivated to run to receive the reward. The reward tube was adjusted before each session to ensure animals could reach the water droplets upon delivery. Mice were closely monitored to receive at least $1 \mathrm{~mL}$ of water each day to avoid the weight dropping below $10 \%$ of their initial body weight. At least one day per week animals received ad libitum water; food was always available. The day after the craniotomy, and on subsequent recording days, an acute 16-channel silicon probe (Buzsaki16-A16 probe, A1 16 linear probe or a A2x2 tetrode probe, NeuroNexus) was painted with DiI or DiO, connected to an RA16-AC preamplifier (Tucker-Davis Technologies) and gradually lowered into the hippocampal formation (Table S1). Up to two recording sessions were carried out per day (e.g. one hemisphere per session). The hippocampus was identified based on approximate depth, high power theta oscillations during running, sharp waves during rest, polarity of theta and sharp waves across the different channels, and the presence of high firing neurons in an $\sim 100 \mu \mathrm{m}$ band corresponding to the stratum pyramidale. Signals were amplified x1000 (Lynx-8 amplifiers, Neuralynx), band-pass filtered ( $0.5 \mathrm{~Hz}$ to $8 \mathrm{kHz}$ ), digitized at $20 \mathrm{kHz}$ with a Power1401 and recorded with Spike2. Jet ball movement, position along the virtual track, a lick sensor and reward delivery were synchronized to the recordings. A video camera was used to monitored behavior. Two mice that failed to learn goal-directed navigation (cases TV147 and TV148, both female 23 mo ntg mice) were instead used for headfixed recordings as above. Silicon probe recording sites were confirmed by examining $\mathrm{DiI} / \mathrm{DiO}$ fluorescence in serially processed brain sections.

Data analysis.

Data were analyzed in Mathematica (Wolfram Research), Python, MATLAB (The MathWorks), and Spike2.

Local field potentials (LFPs): In Spike2, DC shifts were removed with $0.3 \mathrm{~s}$ sliding windows then channels were downsampled to $1.25 \mathrm{kHz}$. Channels were either exported for analysis with other programs, or analyzed further in Spike2. Theta epochs were defined by the power ratio of theta $(5-12 \mathrm{~Hz})$ over delta $(2-4 \mathrm{~Hz})$ in $2 \mathrm{~s}$ windows (root mean square (rms) amplitude) being greater than 2 . To calculate the peak theta frequency, LFPs recorded with glass electrodes were sampled at different depths of CA1d, predominantly from stratum pyramidale. Up to 5 theta epochs were sampled per recording, ranging from 4 to $34 \mathrm{~s}$ to define each epoch. A Hanning 
window (FFT size 2048, $0.6 \mathrm{~Hz}$ resolution) was used to compute the power spectral density in Spike2. The theta peak frequency was measured directly from the curve (interpolated with a cubic spline). Values obtained from 2-4 recordings per mouse were binned and averaged for low running speeds $(4-6 \mathrm{~cm} / \mathrm{s})$ and 'high' speeds $(6-10 \mathrm{~cm} / \mathrm{s})$. We also measured the theta peak from 6 mice ( $3 \mathrm{ntg}, 3 \mathrm{tg}$ ) running in virtual reality; 3 theta epochs were randomly sampled from 1 recording per mouse from a representative channel of an acute silicon probe targeted to distal CA1d. Theta epochs were between 10 and $218 \mathrm{~s}$ (mean of $94 \pm 61 \mathrm{~s}$ ). Actual speed could not be determined for these recordings. Ripples (band-pass filtered, 130-230 Hz) were detected from glass electrode LFP recordings by selecting periods where the rms amplitude (power) was greater than 3 standard deviations above the mean power. At least 2 recordings were sampled per animal, ranging from 31 to 94 detected ripples.

Hilbert-Huang transform (Long et al., 2008). Empirical mode decomposition (EMD) was carried out in Python using the emd package (https://gitlab.com/emd-dev/emd) and its dependencies (Quinn et al., 2021). Sampled glass electrode recordings ranged from 14 to 100 $\mathrm{s}$ of unfiltered LFP containing mostly movement periods. For silicon probe recordings, sampled LFPs containing running periods on the jet ball ranged from 57 to $182 \mathrm{~s}$. To obtain intrinsic mode functions (IMFs), the following masks were used for masked EMD (emd.sift.mask_sift): $(350,200,70,40,30,7,1)$ divided by the sampling rate. Instantaneous amplitude, frequency and phase were obtained for each IMF using emd.spectra.frequency_transform with the Normalized-Hilbert Transform (nht). We excluded IMF1 as it contained mostly noise, and excluded any mid-gamma range IMF that had $50 \mathrm{~Hz}$ electrical noise or poor movement periods (low signal to noise ratio). Phase amplitude coupling was analyzed using emd.spectra.hilberthuang, binning the theta IMF instantaneous phase values.

Single neuron glass electrode recordings. Recording locations were estimated from at least two of the following features: relative depth from a juxtacellularly-labelled recovered cell on the same pipette tract; LFP profile (e.g. positive sharp waves (deep layers) or negative going sharp waves (superficial layers), presence of ripples (highest amplitude in pyramidal cel layers), shape and amplitude of theta oscillations, cross frequency coupling of mid-gamma oscillations to the peak of theta cycles (CA1 stratum pyramidale), presence or absence of 'dentate spikes' for the dentate gyrus); evidence of a pipette tract and/or a cluster of weaklylabeled cells marking a recording location. Unlabeled/non-recovered prinicipal cells were compared to recovered (labeled) cells based on the presence or absence of complex spike bursts. Only data acquired before juxtacellular labeling were used for analysis. For firing rates, spikes within a complex spike (CS) burst were counted individually.

Acute silicon probe recordings. Spikes were detected, sorted, and clustered offline using Kilosort2 (Stringer et al., 2019). Subsequently, interactive visualization and manual curation of the data were carried out using phy software (Rossant et al., 2016) in order to obtain wellisolated and stable units based on refractory periods, spike waveform and cross-correlations (Csicsvari et al., 1999). Units with firing rates < $0.1 \mathrm{~Hz}$ were excluded from further analysis. Data analyses were performed using built-in or custom-written software in MATLAB and Spike2. Firing rates (spikes/s) were computed across 18 sequential bins: We split each run into 15 spatial bins covering the virtual corridor followed by 3 temporal bins $(1 \mathrm{~s}$ each) covering the end of the corridor corresponding to the reward location (the virtual environment was locked for 3 seconds when mice reached the end of the corridor in order to 
receive the water reward). Units were classified as complex spike (CS) cells if they showed a prominent peak between 3-8 $\mathrm{ms}$ in their spike time autocorrelograms typically followed by a relatively fast decay (Chen et al., 2013; Csicsvari et al., 1999). Units were compared to a separate dataset from (Lasztoczi and Klausberger, 2017), who defined putative pyramidal cells (PCs, Table S1) as units with "an overall firing rate $<3 \mathrm{~Hz}$, a spike width at $90 \%$ of the peak amplitude above $0.5 \mathrm{~ms}$, and an event autocorrelogram value below $10 \mathrm{~ms}$ ".

Place cell classification. Significant peak firing rates along the virtual corridor were computed by a permutation test as described in (Ozdemir et al., 2020). Each unit's firing rate was calculated across 18 spatio-temporal bins. Then, we randomly shuffled these time windows within a run for every trial, calculating a surrogate firing rate. Upon repeating this procedure 10,000 times, we obtained the $P$ values of spatial firing modulation by comparing the actual firing rate to the distribution of surrogate rates. Subsequently, significance limits were corrected using a false discovery rate method for multiple comparisons. Well-isolated units were deemed place cells if they had a significantly higher firing rate in at least one spatial bin along the virtual corridor.

Theta coupling. A representative silicon probe site was selected for theta coupling analysis based on the profile of the unfiltered LFP, the extrapolated position from the recovered probe site (DiO or DiI tract), and the probe map. Mostly positive deflections in the LFP during nonrunning periods and typically high power theta oscillations during running indicated a likely stratum pyramidale or stratum oriens location. After detecting theta epochs as for glass electrode recordings above, theta phase was calculated by linear interpolation between troughs of the band-pass-filtered $(5-12 \mathrm{~Hz})$ theta oscillations, with $0^{\circ}$ and $360^{\circ}$ set as the troughs. The Rayleigh test was used to test for uniformity of circular phase distributions; the mean phase and mean vector length ( $\mathrm{r}$ ) were used as measures of the preferred phase and coupling strength, respectively (using custom scripts written in Mathematica). For ntg mice, we analyzed 968 to $1,641 \mathrm{~s}$ duration theta periods (6,740 to 10,943 theta cycles), excluding CS units and non-CS units that had less than 72 and 241 spikes, respectively. For tg mice, we sampled 291 to 1,370 s duration theta periods (2,037 to 9,341 theta cycles), excluding CS cells and non-CS cells with less than 45 and 168 spikes, respectively.

Behavioral tasks.

Spatial novelty preference Y-maze task. This task was designed to assess short-term spatial memory with the expectation that normal mice prefer novel over familiar spatial environments (Bannerman et al., 2008; Sanderson et al., 2007). A solid black plastic Y-maze (30 cm arms, $7 \mathrm{~cm}$ wide, $20 \mathrm{~cm}$ high walls) was positioned $17 \mathrm{~cm}$ from the floor. There were no intra-maze cues except for a $20 \mathrm{~cm}$ high magenta block that blocked one of the arms. Prominent extra-maze cues were used. One arm was designated as the 'novel arm', another the 'start arm', and the third as the 'other arm'. The novel arm was blocked off and the mouse was placed in the start arm and was able to freely explore the start and other arms (exposure phase). After 5 minutes, the block was removed and mice could explore all 3 arms (test phase). Each mouse was only tested once, and arm assignment was counterbalanced for genotype and cohort. The maze was cleaned with ethanol before each test. Time spent in each arm was calculated manually or using ezTrack (Pennington et al., 2019); total distance traveled (path length) was calculated using ezTrack. We excluded 3 mice from the path length analysis due to obstructions in the videos. 
Water escape Y-maze task. This task was used to assess spatial reference memory without the confound of anxiety-related thigmotaxis, which is sometimes evident in the open field water maze (Lyon et al., 2011; Pritchett et al., 2016; Sri et al., 2019). An enclosed Y-maze made of clear Perspex ( $30 \mathrm{~cm}$ arms, $8 \mathrm{~cm}$ wide, $20 \mathrm{~cm}$ high walls) was filled with water made opaque by mixing in white 'ready mix paint' (Reeves). A hidden inverted glass beaker $(\sim 6 \mathrm{~cm}$ diameter) was kept submerged at the end of one of the arms ('goal arm'). Extra-maze cues were kept constant. At the start of each trial, the mouse was placed in one of the other two arms ('start arms'). The start arm was allocated pseudorandomly across trials for each mouse with no more than 2 consecutive starts from the same arm and equal numbers of starts from the arm to the left and right of the target arm in each block of trials). The goal arm remained the same for each animal, but the allocation of the goal arm was counterbalanced for genotype and cohort. The mouse was allowed to swim freely until it reached the hidden platform. However, if it did not reach the platform by $90 \mathrm{~s}$ it was guided by the experimenter. The mouse was allowed to remain on the platform for $30 \mathrm{~s}$ before being removed. There were 5 trials/d for 10 days (acquisition training) with an inter-trial interval of $15 \mathrm{~s}$. For each trial, the first arm entered (choice) was scored 1 for the goal arm and 0 for the other arm or re-entered the start arm. A block was defined as 5 trials, with performance expressed as percentage of correct first choices (choice accuracy). On day 11, a probe trial was performed, whereby the platform was removed and the mouse was allowed to swim freely for $60 \mathrm{~s}$. One ntg mouse was excluded from analysis as it failed to make choices on days 4-10.

Non-matching to place T-maze task (rewarded alternation). This task assessed spatial working memory (Reisel et al., 2002). The T maze consisted of a $50 \times 10 \mathrm{~cm}$ start arm and two identical $30 \times 10 \mathrm{~cm}$ goal arms. Walls were $10 \mathrm{~cm}$ high, and the maze was raised $44 \mathrm{~cm}$ off the floor. Group-housed mice were maintained on a restricted feeding schedule to $\sim 90 \%$ of their freefeeding weight and fed every day at 16:00. On the $6^{\text {th }}$ day after starting food restriction, mice were habituated to $50 \%$ sweetened condensed milk in a dish in their home cage in the holding room. The next day, milk was provided in their cages inside the behavior-testing room (context 1). The following day, cagemates were group habituated to the T-maze with $0.5 \mathrm{ml}$ milk rewards in plastic dishes at the ends of both goal arms. The room was well-lit and contained extra-maze cues. An odorless cleaning solution was used to clean the maze before testing different cages. After several more days on food restriction, non-matching to place testing began. Each trial consisted of a 'forced run' and a 'choice run', with 4 trials per day defined as a session. In the forced run, one goal arm was blocked with a wooden block. Mice were placed into a blocked-off start box at the far end of the start arm. After this start block was removed, mice had to run to the unblocked goal arm for a $0.1 \mathrm{ml}$ reward. The blocked goal arm was determined by a pseudorandom sequence (with equal numbers of left and right turns per session, with no more than 2 consecutive turns in the same direction). If the mouse did not initiate a run within $60 \mathrm{~s}$ after removing the start black, the mouse would be re-tested after all the other cagemates were tested in that session. For all trials, the delay time in task initiation was measured from start block removal until leaving the start box area. After sampling the reward on the forced run, the mouse was removed from the maze. The mouse was placed back at the far end of the start arm and now had to choose between the goal arms (now with both arms unblocked). The average time between sampling the reward on the forced run to being free to initiate the choice run from the far end of the start arm was $16 \mathrm{~s}$ (from $n=3,240$ trials). The mouse was rewarded for choosing the unvisited (previously blocked) arm, i.e. for alternating. An alternation score was calculated by scoring 1 for 
alternating and 0 for not alternating. Mice were tested one trial at a time, so that all cagemates were tested once before starting their second trial ( $\sim 4-8 \mathrm{~min}$ inter-trial interval, depending on cage size). A total of 10 sessions were undertaken for each mouse (40 trials total), and analyzed as blocks of 4 trials. The same mice were tested at 3 different ages, with the $2^{\text {nd }}$ and $3^{\text {rd }}$ tests no requiring habituation. Since ntg and tg mice reached high levels of performance (see Results), differences between genotypes might be revealed by using an unfamiliar context. In context 2, a different testing room was used featuring different extra-maze cues, an R-Carvone odor, and prominent intra-maze cues (white stripes on the maze floor and a red cross on the block), and cleaning was carried out with ethanol instead of the odorless cleaning solution.

Elevated plus maze. To test anxiety-related behavior, mice familiar to other behavioral tasks were placed individually in the center of an elevated plus maze facing an open arm. Two versions were used: one had $36 \times 7 \mathrm{~cm}$ open and closed arms, $21.5 \mathrm{~cm}$ high gray wooden walls for the closed arms, and positioned $69 \mathrm{~cm}$ from the floor (for 3 mo mice). The other had $32 \times 9$ $\mathrm{cm}$ arms, $19.5 \mathrm{~cm}$ high black plastic walls for the closed arms, and was $92 \mathrm{~cm}$ from the floor (for 12 mo mice). The time spent in open and closed arms was measured over $5 \mathrm{~min}$, excluding the junction.

\section{Histology and imaging.}

Tissue processing. Mice were deeply anesthetized with sodium pentobarbital ( $50 \mathrm{mg} / \mathrm{kg}$, i.p.) and transcardially perfused with saline followed by $4 \%$ paraformaldehyde, $15 \% \mathrm{v} / \mathrm{v}$ saturated picric acid, and $0.05 \%$ glutaraldehyde in $0.1 \mathrm{M}$ phosphate buffer $(\mathrm{PB}), \mathrm{pH}$ 7.4. Some brains were post-fixed overnight in fixative lacking the glutaraldehyde. After washing in $0.1 \mathrm{M} \mathrm{PB}$, $70 \mu \mathrm{m}$ coronal sections were cut using a Leica Microsystems VT $1000 \mathrm{~S}$ vibratome and stored in $0.1 \mathrm{M} \mathrm{PB}$ with $0.05 \%$ sodium azide at $4^{\circ} \mathrm{C}$. To visualize neurobiotin-labeled neuronal processes, tissue sections were permeabilized in Tris-buffered saline $(0.9 \% \mathrm{NaCl}$ buffered with $50 \mathrm{mM}$ Tris, $\mathrm{pH} 7.4$; TBS) with $0.3 \%$ Triton X-100 (TBS-Tx) or through rapid $2 x$ freeze-thaw (FT) over liquid nitrogen (cryoprotected in $20 \%$ sucrose in 0.1 M PB) then streptavidinconjugated Alexa Fluor 488 was applied at 1:1000 dilution in TBS-Tx (or TBS if permeabilized with FT) for $4 \mathrm{~h}$ at room temperature (RT) or overnight at $4^{\circ} \mathrm{C}$. Sections were washed in TBS/TBS-Tx and mounted to slides in Vectashield (Vector Laboratories).

Immunohistochemistry. Sections were blocked for $1 \mathrm{~h}$ in $20 \%$ normal horse serum (NHS) in TBS/TBS-Tx followed by $3 \mathrm{~d}$ incubation at $4^{\circ} \mathrm{C}$ in primary antibody solution containing $1 \%$ NHS in TBS/TBS-Tx. The following primary antibodies (and dilutions) were used: Mouse anti-AT8 1:5000 (MN1020, lot ND 169248, Thermo Fisher Scientific; this antibody specifically recognizes Tau phosphorylated at serine 202 and threonine 205 residues of human Tau (Goedert et al., 1995)), goat anti-Calbindin 1:500 (Calbindin-Go-Af1040, Frontier Institute), rabbit anti-Calbindin 1:5000 (CB-38, lot No.5.5, Swant), rabbit anti-Calretinin 1:1000 (7699/3H, lot 18299, Swant), rabbit anti-Ctip2 1:1000 (25B6, ab18465, Abcam), rabbit anti-Olig2 1:500 (AB9610, lot 0603024913, Millipore), guinea pig anti-Parvalbumin 1:250 (195004/1-19, Synaptic Systems), rabbit anti-Parvalbumin (PV 27, lot 2014, Swant), rabbit anti-PCP4 1:1000 (sc-293258, lot GO814, Santa Cruz), goat-anti Satb1 1:250 (N-14, sc-5989, Santa Cruz), rabbit anti-Satb2 1:1000 (ab34735, Abcam), chicken anti-Tyrosine hydroxylase 1:500 (ab76442, Abcam), rabbit anti-Wfs1 1:1000 (11558-1-AP, lot 00043335, Proteintech). Specificity references can be found in the following publications: (Salib et al., 2019; Unal et al., 2015; Viney et al., 2013; Viney et al., 2018). Sections were washed 3 times in TBS/TBS-Tx then incubated in secondary antibody solution containing $1 \%$ NHS in TBS/TBS-Tx for $4 \mathrm{~h}$ RT or overnight at 
$4^{\circ} \mathrm{C}$. The following secondary antibodies (and dilutions) were used in various combinations (all raised in donkey): 1:250 anti-guinea pig and anti-rabbit DyLight 405 1:250 (706-475-148), anti-rabbit Violet421 1:100-200 (713-675-152, 705-605-147, 711-475-152), anti-mouse and antirabbit Alexa Fluor 488 1:1000 (711-605-152, 711-545-152), anti-rabbit and anti-chicken Cy3 1:400 (711-165-152, 703-165-155 ), anti-goat Cy5 1:250 (705-605-147), anti-goat Cy5 1:250 (705605-147), anti-guinea pig and anti-rabbit Alexa Fluor 647 1:250 (706-475-148, 711-605-152) from Jackson ImmunoResearch and Alexa Fluor 405 (A31556) from Invitrogen. After 3 washes, sections were mounted in Vectashield.

Fluorescence microscopy. Sections were visualized and imaged with widefield epifluorescence using a Leitz DMRB microscope (Leica Microsystems) equipped with PL Fluotar objectives (magnification/numerical aperture: $5 x / 0.15,10 x / 0.3,20 x / 0.5,40 x / 0.7$; OpenLab software) or an AXIO Observer Z1 microscope (LSM 710; Zeiss) equipped with Plan-Apochromat 10x/0.3, $20 x / 0.8$ and $40 x / 1.4$ objectives (Axiovision or ZEN Blue 2.6 software). For confocal microscopy, the LSM 710 was used with Plan-Apochromat 40x/1.4, 63x/1.4, and 100x/1.46 objectives (ZEN 20085.0 or ZEN Black 14.0 software). Laser lines (solid-state $405 \mathrm{~nm}$, argon $488 \mathrm{~nm}, \mathrm{HeNe} 543 \mathrm{~nm}$ and HeNe 633nm) were configured with the appropriate beamsplitters. The pinhole was set to $\sim 1$ Airy Unit for each channel.

Cell counts. To count the number of CA1 pyramidal cells in age-matched ntg and tg mice (Fig. $2 \mathrm{H}$ ), we imaged SATB2 immunopositive nuclei with a 20x/0.5 lens focused on the top of 70 $\mu \mathrm{m}$-thick coronal sections containing CA1d between CA2 and SUBd. Counting was carried out using the Cell Counter plugin in Fiji (ImageJ). We averaged counts from 3 hemispheres per mouse, then compared the resulting mean counts from 3 mice per genotype.

Single- and double-labeling pre-embedding immunohistochemistry and electron microscopy. Floating sections from cases TT21D and TT33G were washed 3x in TBS and blocked in 5\% normal goat serum (NGS) in TBS for $45 \mathrm{~min}$. Next, sections were incubated with AT8 and/or Olig2 primary antibodies in TBS for $6 \mathrm{~d}$ at $4^{\circ} \mathrm{C}$. The following immunoreactions were performed: (1) One primary antibody with immunogold labelling followed by silver intensification; (2) one primary antibody with peroxidase reaction; (3) two primary antibodies, visualized by a silverintensified immunogold reaction, followed by an immunoperoxidase reaction; (4) control, no primary antibody, immunogold and biotinylated secondary antibodies followed by silverintensification. After incubation with primary antibodies, sections were rinsed three times in TBS and blocked for $30 \mathrm{~min}$ at RT in $0.1 \%$ Cold Water Fish Skin Gelatin (CWFS) solution containing $0.8 \%$ NGS and $0.05 \%$ sodium azide in TBS to reduce non-specific background reactions. Next, sections were incubated overnight at $4^{\circ} \mathrm{C}$ in 1:300 biotinylated goat anti-rabbit IgG (Vector Labs, BA-1000) and 1:200 donkey anti-mouse ultrasmall immunogold (Aurion, 100.322) in CWFS solution. Sections were washed several times in TBS and once in 0.1 M PB followed by incubation with $2 \%$ glutaraldehyde in PB to fix the antibodies conjugated to immunogold particles. After repeated washes in TBS, sections were incubated overnight at $4^{\circ} \mathrm{C}$ in avidin-biotinylated horseradish peroxidase complex (Vectastain ABC Elite kit, Vector Laboratories) in TBS. To visualize immunogold particles, they were intensified with silver: first the sections were treated with enhancement conditioning solution (ECS; Aurion) diluted $10 \mathrm{x}$ with distilled water for $3 \times 5 \mathrm{~min}$. To enlarge the gold particles further, sections were then incubated in silver enhancement solution (SE-LM, Aurion) for $20 \mathrm{~min}$ at $20^{\circ} \mathrm{C}$ and washed in ECS. Subsequently, peroxidase was visualized using 3,3-diaminobenzidine (DAB; $0.5 \mathrm{mg} / \mathrm{ml}$, Sigma-Aldrich) as chromogen developed with $0.01 \% \mathrm{H}_{2} \mathrm{O}_{2}$. The same method and reagents 
were used for single and double labeling. After washing sections in $\mathrm{PB}$, they were treated with $0.5 \% \mathrm{OsO}_{4}$ (a fixative and heavy metal contrasting agent) in $0.1 \mathrm{M}$ PB for 20 min on ice to control reaction time. Next, dehydration of sections was carried out in ascending ethanol series $(50 \%, 70 \%, 90 \%, 95 \%, 100 \%)$ and in acetonitrile. To enhance contrast for electron microscopy, sections were incubated in $1 \%$ uranyl acetate diluted in $70 \%$ ethanol for 25 min between the $70 \%$ and $90 \%$ ethanol steps. Subsequently, sections were placed in epoxy resin (Durpucan AMC, Fluka, Sigma-Aldrich), incubated overnight at RT and transferred onto slides. For polymerization, sections were incubated at $60^{\circ} \mathrm{C}$ for $2 \mathrm{~d}$. Selected regions of proximal SUBd and/or distal CA1d were re-embedded into Durcupan blocks. A series of $\sim 50$ nm-thick sections were cut with an ultramicrotome (Leica Ultracut UTC) and collected on pioloform-coated copper grids. Finally, sections were counterstained with lead citrate and studied on a Jeol 1010 transmission electron microscope equipped with a digital GATAN Orius camera (Department of Physiology, Anatomy and Genetics, Oxford University).

\section{QUANTIFICATION AND STATISTICAL ANALYSIS}

Mean and standard deviation (s.d.) are reported as mean \pm s.d.; median and interquartile range (IQR) are reported as median [IQR]. Experimental units (e.g. mice, cells) are specified in the text after the $\mathrm{n}$ values. Statistical analysis was carried out in Mathematica, GraphPad Prism, and SPSS (version 28, IBM). The alpha was set to 0.05 . For data that approximated a normal distribution, unpaired Student's $\mathrm{T}$ tests were used to compare two groups, otherwise Mann-Whitney tests were used. For comparisons of more than two groups we used Analysis of Variance (ANOVA) for parametric data, and the Kruskal-Wallis test for non-parametric data, but only if groups had similar variances. For analysis of circular data, we used the Rayleigh test $(Z)$. The following test statistics are specified in the text and refer to the following tests: $\chi^{2}$, Kruskal-Wallis; $D$, Kolmogorov-Smirnov; $U$, Mann-Whitney; $t$, unpaired T test; $F$, ANOVA. 
bioRxiv preprint doi: https://doi.org/10.1101/2021.11.24.469849; this version posted November 25, 2021. The copyright holder for this preprint (which was not certified by peer review) is the author/funder, who has granted bioRxiv a license to display the preprint in perpetuity. It is made available under aCC-BY-NC-ND 4.0 International license.

KEY RESOURCES TABLE 


\begin{tabular}{|c|c|c|}
\hline REAGENT or RESOURCE & SOURCE & IDENTIFIER \\
\hline \multicolumn{3}{|l|}{ Antibodies } \\
\hline AT8 & Thermo Fisher Scientific & $\begin{array}{l}\text { MN1020, RRID: } \\
\text { AB_223647 }\end{array}$ \\
\hline Calbindin & Frontier Institute & $\begin{array}{l}\text { Calbindin-Go- } \\
\text { Af1040, RRID: } \\
\text { AB_2571569 }\end{array}$ \\
\hline Calbindin & Swant & $\begin{array}{l}\text { CB-38, RRID: } \\
\text { AB_10000340 }\end{array}$ \\
\hline Calretinin & Swant & $\begin{array}{l}\text { 7699/3H, RRID: } \\
\text { AB_10000321 }\end{array}$ \\
\hline Ctip2 & Abcam & $\begin{array}{l}\text { ab18465, RRID: } \\
\text { AB_2064130 }\end{array}$ \\
\hline Olig2 & Millipore & $\begin{array}{ll}\text { AB9610, } & \text { RRID: } \\
\text { AB_570666 } & \end{array}$ \\
\hline Parvalbumin & Synaptic Systems & $\begin{array}{l}\text { 195004/1-19, } \\
\text { RRID: AB_2156476 }\end{array}$ \\
\hline Parvalbumin & Swant & $\begin{array}{l}\text { PV 27, RRID: } \\
\text { AB_2631173 }\end{array}$ \\
\hline PCP4 & Santa Cruz & GO814 \\
\hline Satb1 & Santa Cruz & $\begin{array}{l}\text { sc-5989, RRID: } \\
\text { AB_2184337 }\end{array}$ \\
\hline Satb2 & Abcam & $\begin{array}{l}\text { ab34735, RRID: } \\
\text { AB_2301417 }\end{array}$ \\
\hline Tyrosine hydroxylase & Abcam & $\begin{array}{l}\text { ab76442, RRID: } \\
\text { AB_1524535 }\end{array}$ \\
\hline Wfs1 & Proteintech & $\begin{array}{l}\text { 11558-1-AP, RRID: } \\
\text { AB_2216046 }\end{array}$ \\
\hline \multicolumn{3}{|c|}{ Chemicals, peptides, and recombinant proteins } \\
\hline Neurobiotin tracer & Vector Laboratories & $\begin{array}{l}\text { \#SP-1120; RRID: } \\
\text { AB_2313575 }\end{array}$ \\
\hline Isoflurane inhalation anesthesia & Teva Ltd. & $\begin{array}{l}\text { https:// products.t } \\
\text { evauk.com/p/Cat } \\
\text { egory?id=185 }\end{array}$ \\
\hline Vetergesic (0.3 mg/ml Buprenorphine) & Ceva & \\
\hline Marcain (Bupivacaine) & Aspen & \#PS09728 \\
\hline Refobacin bone cement & Zimmer Biomet & \#3003940002-3 \\
\hline Tetric EvoFlow dental cement & Ivoclar Vivadent & A1 \\
\hline DiI tracer & Life Technologies & \#V22889 \\
\hline DiO tracer & Life Technologies & \#V22889 \\
\hline R-Carvone & Sigma-Aldrich & \#124931 \\
\hline Normal horse serum & Vector Laboratories & S-2000 \\
\hline Normal goat serum & Vector Laboratories & S-1000 \\
\hline
\end{tabular}


bioRxiv preprint doi: https:/doi org/10.1101/2021.1124.469849; this version posted November 25,2021 . The copyright holder for this preprint (which was not certified by peer review) is the author/funder, who has granted bioRxiv a license to display the preprint in perpetuity. It is made available under aCC-BY-NC-ND 4.0 International license.

\begin{tabular}{|c|c|c|}
\hline Cold Water Fish Skin Gelatin & Aurion & \#900.033 \\
\hline Enhancement conditioning solution ECS & Aurion & Lot $01207 / 3$ \\
\hline Silver enhancement solution SE-LM & Aurion & $\# 500.022$ \\
\hline Diaminobenzidine & Sigma-Aldrich & D5637-1G \\
\hline \multicolumn{3}{|l|}{ Critical commercial assays } \\
\hline Vectastain ABC Elite kit & Vector Laboratories & $\begin{array}{ll}\text { Cat\# } & \text { PK6100; } \\
\text { RRID: AB_2336819 }\end{array}$ \\
\hline Vectashield Antifade Mounting Medium & Vector Laboratories & $\begin{array}{lr}\text { Cat\# } & \text { H-1000; } \\
\text { RRID: AB_2336789 }\end{array}$ \\
\hline \multicolumn{3}{|l|}{ Experimental models: Organisms/strains } \\
\hline C57BL6j mice & $\begin{array}{ll}\text { Charles } & \text { River } \\
\text { Laboratories } & \end{array}$ & $\begin{array}{l}\text { https://www.criv } \\
\text { er.com/ }\end{array}$ \\
\hline THY-Tau22 mice & $\begin{array}{l}\text { (Schindowski et al., } \\
\text { 2006) }\end{array}$ & $\begin{array}{l}\text { http://www.infor } \\
\text { matics.jax.org/alle } \\
\text { le/MGI:3717232 }\end{array}$ \\
\hline \multicolumn{3}{|l|}{ Software and algorithms } \\
\hline Fiji & ImageJ & $\begin{array}{l}\text { https:/ /imagej.net } \\
\text { / software/fiji/ }\end{array}$ \\
\hline Mathematica & Wolfram Research & $\begin{array}{l}\text { https://www.wolf } \\
\text { ram.com/mathem } \\
\text { atica/ }\end{array}$ \\
\hline MATLAB & Mathworks & $\begin{array}{l}\text { www.mathworks.c } \\
\text { om/products/ } \\
\text { matlab.html }\end{array}$ \\
\hline Zen 2008, Zen Black, Zen Blue, Axiovision & Zeiss & www.zeiss.co.uk \\
\hline Spike2 & $\begin{array}{l}\text { Cambridge Electronic } \\
\text { Design }\end{array}$ & http://ced.co.uk/ \\
\hline Kilosort2 & (Stringer et al., 2019) & $\begin{array}{l}\text { https://github.co } \\
\text { m/MouseLand/Ki } \\
\text { losort }\end{array}$ \\
\hline phy & (Rossant et al., 2016) & $\begin{array}{l}\text { https://klusta.rea } \\
\text { dthedocs.io/en/lat } \\
\text { est/ }\end{array}$ \\
\hline Python & & $\begin{array}{l}\text { https://www.pyt } \\
\text { hon.org/ }\end{array}$ \\
\hline ezTrack & (Pennington et al., 2019) & $\begin{array}{l}\text { https://github.co } \\
\text { m/denisecailab/e } \\
\text { zTrack }\end{array}$ \\
\hline EMD & (Quinn et al., 2021) & $\begin{array}{l}\text { https://gitlab.com } \\
\text { /emd-dev/emd }\end{array}$ \\
\hline SPSS & IBM & $\begin{array}{l}\text { https://www.ibm. } \\
\text { com/products/sps } \\
\text { s-statistics }\end{array}$ \\
\hline
\end{tabular}


bioRxiv preprint doi: https://doi.org/10.1101/2021.11.24.469849; this version posted November 25, 2021. The copyright holder for this preprint (which was not certified by peer review) is the author/funder, who has granted bioRxiv a license to display the preprint in perpetuity. It is made available under aCC-BY-NC-ND 4.0 International license.

\begin{tabular}{|l|l|l|}
\hline Prism 7 & Prism 7 GraphPad & $\begin{array}{l}\text { https://www.gra } \\
\text { phpad.com/ }\end{array}$ \\
\hline Other & NeuroNexus & $\begin{array}{l}\text { https://neuronexu } \\
\text { s.com/ }\end{array}$ \\
\hline Buzsaki16-A16 silicon probe & NeuroNexus & $\begin{array}{l}\text { https://neuronexu } \\
\text { s.com/ }\end{array}$ \\
\hline A1x16 linear silicon probe & NeuroNexus & $\begin{array}{l}\text { https:/ neuronexu } \\
\text { s.com/ }\end{array}$ \\
\hline A2x2 tetrode silicon probe & \multicolumn{2}{|l}{}
\end{tabular}




\section{References}

Ahnaou, A., Moechars, D., Raeymaekers, L., Biermans, R., Manyakov, N.V., Bottelbergs, A., Wintmolders, C., Van Kolen, K., Van De Casteele, T., Kemp, J.A., et al. (2017). Emergence of early alterations in network oscillations and functional connectivity in a tau seeding mouse model of Alzheimer's disease pathology. Sci Rep 7, 14189.

Arakhamia, T., Lee, C.E., Carlomagno, Y., Duong, D.M., Kundinger, S.R., Wang, K., Williams, D., DeTure, M., Dickson, D.W., Cook, C.N., et al. (2020). Posttranslational Modifications Mediate the Structural Diversity of Tauopathy Strains. Cell 180, 633-644 e612.

Arima, K. (1996). Tubular profile of the Gallyas- and tau-positive argyrophilic threads in corticobasal degeneration: An electronmicroscopic study. Neuropathology 16, 65-70.

Arima, K., Nakamura, M., Sunohara, N., Ogawa, M., Anno, M., Izumiyama, Y., Hirai, S., and Ikeda, K. (1997). Ultrastructural characterization of the tau-immunoreactive tubules in the oligodendroglial perikarya and their inner loop processes in progressive supranuclear palsy. Acta Neuropathol 93, 558-566.

Bannerman, D.M., Grubb, M., Deacon, R.M.J., Yee, B.K., Feldon, J., and Rawlins, J.N.P. (2003). Ventral hippocampal lesions affect anxiety but not spatial learning. Behavioural Brain Research 139, 197-

213.

Bannerman, D.M., Niewoehner, B., Lyon, L., Romberg, C., Schmitt, W.B., Taylor, A., Sanderson, D.J., Cottam, J., Sprengel, R., Seeburg, P.H., et al. (2008). NMDA receptor subunit NR2A is required for rapidly acquired spatial working memory but not incremental spatial reference memory. J Neurosci 28, 3623-3630.

Bannerman, D.M., Rawlins, J.N., McHugh, S.B., Deacon, R.M., Yee, B.K., Bast, T., Zhang, W.N., Pothuizen, H.H., and Feldon, J. (2004). Regional dissociations within the hippocampus--memory and anxiety. Neurosci Biobehav Rev 28, 273-283.

Battefeld, A., Klooster, J., and Kole, M.H. (2016). Myelinating satellite oligodendrocytes are integrated in a glial syncytium constraining neuronal high-frequency activity. Nat Commun 7, 11298. Belarbi, K., Burnouf, S., Fernandez-Gomez, F.J., Desmercieres, J., Troquier, L., Brouillette, J., Tsambou, L., Grosjean, M.E., Caillierez, R., Demeyer, D., et al. (2011). Loss of medial septum cholinergic neurons in THY-Tau22 mouse model: what links with tau pathology? Curr Alzheimer Res 8, 633-638.

Berardi, N., Braschi, C., Capsoni, S., Cattaneo, A., and Maffei, L. (2007). Environmental enrichment delays the onset of memory deficits and reduces neuropathological hallmarks in a mouse model of Alzheimer-like neurodegeneration. J Alzheimers Dis 11, 359-370.

Boerner, T., Bygrave, A.M., Chen, J., Fernando, A., Jackson, S., Barkus, C., Sprengel, R., Seeburg, P.H., Harrison, P.J., Gilmour, G., et al. (2017). The group II metabotropic glutamate receptor agonist LY354740 and the D2 receptor antagonist haloperidol reduce locomotor hyperactivity but fail to rescue spatial working memory in GluA1 knockout mice. Eur J Neurosci 45, 912-921.

Booth, C.A., Ridler, T., Murray, T.K., Ward, M.A., de Groot, E., Goodfellow, M., Phillips, K.G., Randall, A.D., and Brown, J.T. (2016). Electrical and Network Neuronal Properties Are Preferentially Disrupted in Dorsal, But Not Ventral, Medial Entorhinal Cortex in a Mouse Model of Tauopathy. J Neurosci 36, 312-324.

Brandon, M.P., Bogaard, A.R., Schultheiss, N.W., and Hasselmo, M.E. (2013). Segregation of cortical head direction cell assemblies on alternating theta cycles. Nat Neurosci 16, 739-748.

Busche, M.A., Wegmann, S., Dujardin, S., Commins, C., Schiantarelli, J., Klickstein, N., Kamath, T.V., Carlson, G.A., Nelken, I., and Hyman, B.T. (2019). Tau impairs neural circuits, dominating amyloidbeta effects, in Alzheimer models in vivo. Nat Neurosci 22, 57-64.

Buzsaki, G. (2015). Hippocampal sharp wave-ripple: A cognitive biomarker for episodic memory and planning. Hippocampus 25, 1073-1188.

Buzsáki, G. (2019). The Brain from Inside Out (New York: Oxford University Press).

Buzsaki, G., Leung, L.W., and Vanderwolf, C.H. (1983). Cellular bases of hippocampal EEG in the behaving rat. Brain Res 287, 139-171. 
Canolty, R.T., Edwards, E., Dalal, S.S., Soltani, M., Nagarajan, S.S., Kirsch, H.E., Berger, M.S., Barbaro, N.M., and Knight, R.T. (2006). High gamma power is phase-locked to theta oscillations in human neocortex. Science 313, 1626-1628.

Caroni, P. (1997). Overexpression of growth-associated proteins in the neurons of adult transgenic mice. J Neurosci Methods 71, 3-9.

Chen, G., King, J.A., Burgess, N., and O'Keefe, J. (2013). How vision and movement combine in the hippocampal place code. Proc Natl Acad Sci U S A 110, 378-383.

Clavaguera, F., Akatsu, H., Fraser, G., Crowther, R.A., Frank, S., Hench, J., Probst, A., Winkler, D.T., Reichwald, J., Staufenbiel, M., et al. (2013). Brain homogenates from human tauopathies induce tau inclusions in mouse brain. Proc Natl Acad Sci U S A 110, 9535-9540.

Csicsvari, J., Hirase, H., Czurko, A., Mamiya, A., and Buzsaki, G. (1999). Oscillatory coupling of hippocampal pyramidal cells and interneurons in the behaving Rat. J Neurosci 19, 274-287.

Degiorgis, L., Karatas, M., Sourty, M., Faivre, E., Lamy, J., Noblet, V., Bienert, T., Reisert, M., von Elverfeldt, D., Buée, L., et al. (2020). Brain network remodelling reflects tau-related pathology prior to memory deficits in Thy-Tau22 mice. Brain 143, 3748-3762.

Ding, S.L., Yao, Z., Hirokawa, K.E., Nguyen, T.N., Graybuck, L.T., Fong, O., Bohn, P., Ngo, K., Smith, K.A., Koch, C., et al. (2020). Distinct Transcriptomic Cell Types and Neural Circuits of the Subiculum and Prosubiculum along the Dorsal-Ventral Axis. Cell Rep 31, 107648.

Ferreira, S., Pitman, K.A., Summers, B.S., Wang, S., Young, K.M., and Cullen, C.L. (2021).

Oligodendrogenesis increases in hippocampal grey and white matter prior to locomotor or memory impairment in an adult mouse model of tauopathy. Eur J Neurosci 54, 5762-5784.

Ferrer, I. (2018). Oligodendrogliopathy in neurodegenerative diseases with abnormal protein aggregates: The forgotten partner. Prog Neurobiol 169, 24-54.

Ferrer, I., Aguilo Garcia, M., Carmona, M., Andres-Benito, P., Torrejon-Escribano, B., Garcia-Esparcia, P., and Del Rio, J.A. (2019). Involvement of Oligodendrocytes in Tau Seeding and Spreading in Tauopathies. Front Aging Neurosci 11, 112.

Frost, B.E., Martin, S.K., Cafalchio, M., Islam, M.N., Aggleton, J.P., and O'Mara, S.M. (2021). Anterior Thalamic Inputs Are Required for Subiculum Spatial Coding, with Associated Consequences for Hippocampal Spatial Memory. J Neurosci 41, 6511-6525.

Goedert, M., Eisenberg, D.S., and Crowther, R.A. (2017). Propagation of Tau Aggregates and Neurodegeneration. Annu Rev Neurosci 40, 189-210.

Goedert, M., Jakes, R., and Vanmechelen, E. (1995). Monoclonal antibody AT8 recognises tau protein phosphorylated at both serine 202 and threonine 205. Neurosci Lett 189, 167-169.

Goodman, M.S., Kumar, S., Zomorrodi, R., Ghazala, Z., Cheam, A.S.M., Barr, M.S., Daskalakis, Z.J., Blumberger, D.M., Fischer, C., Flint, A., et al. (2018). Theta-Gamma Coupling and Working Memory in Alzheimer's Dementia and Mild Cognitive Impairment. Frontiers in Aging Neuroscience 10.

Gotz, J., Chen, F., Barmettler, R., and Nitsch, R.M. (2001). Tau filament formation in transgenic mice expressing P301L tau. J Biol Chem 276, 529-534.

Grueninger, F., Bohrmann, B., Czech, C., Ballard, T.M., Frey, J.R., Weidensteiner, C., von Kienlin, M., and Ozmen, L. (2010). Phosphorylation of Tau at S422 is enhanced by Abeta in TauPS2APP triple transgenic mice. Neurobiol Dis 37, 294-306.

Habib, N., McCabe, C., Medina, S., Varshavsky, M., Kitsberg, D., Dvir-Szternfeld, R., Green, G., Dionne, D., Nguyen, L., Marshall, J.L., et al. (2020). Disease-associated astrocytes in Alzheimer's disease and aging. Nat Neurosci 23, 701-706.

Hamieh, A.M., Camperos, E., Hernier, A.M., and Castagne, V. (2021). C57BL/6 mice as a preclinical model to study age-related cognitive deficits: Executive functions impairment and inter-individual differences. Brain Res 1751, 147173.

Ikeda, K., Akiyama, H., Haga, C., Kondo, H., Arima, K., and Oda, T. (1994). Argyrophilic thread-like structure in corticobasal degeneration and supranuclear palsy. Neurosci Lett 174, 157-159. 
Ising, C., Venegas, C., Zhang, S., Scheiblich, H., Schmidt, S.V., Vieira-Saecker, A., Schwartz, S., Albasset, S., McManus, R.M., Tejera, D., et al. (2019). NLRP3 inflammasome activation drives tau pathology. Nature 575, 669-673.

Jeffery, K.J., Donnett, J.G., and O'Keefe, J. (1995). Medial septal control of theta-correlated unit firing in the entorhinal cortex of awake rats. Neuroreport 6, 2166-2170.

Joshi, A., Salib, M., Viney, T.J., Dupret, D., and Somogyi, P. (2017). Behavior-Dependent Activity and Synaptic Organization of Septo-hippocampal GABAergic Neurons Selectively Targeting the Hippocampal CA3 Area. Neuron 96, 1342-1357 e1345.

Kjelstrup, K.G., Tuvnes, F.A., Steffenach, H.A., Murison, R., Moser, E.I., and Moser, M.B. (2002). Reduced fear expression after lesions of the ventral hippocampus. Proc Natl Acad Sci U S A 99, 10825-10830.

Lapray, D., Lasztoczi, B., Lagler, M., Viney, T.J., Katona, L., Valenti, O., Hartwich, K., Borhegyi, Z., Somogyi, P., and Klausberger, T. (2012). Behavior-dependent specialization of identified hippocampal interneurons. Nat Neurosci 15, 1265-1271.

Lasztoczi, B., and Klausberger, T. (2017). Distinct gamma oscillations in the distal dendritic fields of the dentate gyrus and the CA1 area of mouse hippocampus. Brain Struct Funct 222, 3355-3365. Leutgeb, S., and Mizumori, S.J. (1999). Excitotoxic septal lesions result in spatial memory deficits and altered flexibility of hippocampal single-unit representations. J Neurosci 19, 6661-6672.

Lin, W.L., Lewis, J., Yen, S.H., Hutton, M., and Dickson, D.W. (2003). Filamentous tau in oligodendrocytes and astrocytes of transgenic mice expressing the human tau isoform with the P301L mutation. Am J Pathol 162, 213-218.

Long, S., Wu, Z., and Huang, N. (2008). Hilbert-Huang transform. Scholarpedia 3, 2544. Lopes-Dos-Santos, V., van de Ven, G.M., Morley, A., Trouche, S., Campo-Urriza, N., and Dupret, D. (2018). Parsing Hippocampal Theta Oscillations by Nested Spectral Components during Spatial Exploration and Memory-Guided Behavior. Neuron 100, 940-952 e947.

Lyon, L., Burnet, P.W., Kew, J.N., Corti, C., Rawlins, J.N., Lane, T., De Filippis, B., Harrison, P.J., and Bannerman, D.M. (2011). Fractionation of spatial memory in GRM2/3 (mGlu2/mGlu3) double knockout mice reveals a role for group II metabotropic glutamate receptors at the interface between arousal and cognition. Neuropsychopharmacology 36, 2616-2628.

Menkes-Caspi, N., Yamin, Hagar G., Kellner, V., Spires-Jones, Tara L., Cohen, D., and Stern, Edward A. (2015). Pathological Tau Disrupts Ongoing Network Activity. Neuron 85, 959-966.

Mizuseki, K., and Buzsaki, G. (2013). Preconfigured, skewed distribution of firing rates in the hippocampus and entorhinal cortex. Cell Rep 4, 1010-1021.

Moscoso, A., Silva-Rodriguez, J., Aldrey, J.M., Cortes, J., Fernandez-Ferreiro, A., Gomez-Lado, N., Ruibal, A., Aguiar, P., and Alzheimer's Disease Neuroimaging, I. (2019). Staging the cognitive continuum in prodromal Alzheimer's disease with episodic memory. Neurobiol Aging 84, 1-8. Nishimura, M., Tomimoto, H., Suenaga, T., Namba, Y., Ikeda, K., Akiguchi, I., and Kimura, J. (1995). Immunocytochemical characterization of glial fibrillary tangles in Alzheimer's disease brain. Am J Pathol 146, 1052-1058.

Ozdemir, A.T., Lagler, M., Lagoun, S., Malagon-Vina, H., Lasztoczi, B., and Klausberger, T. (2020). Unexpected Rule-Changes in a Working Memory Task Shape the Firing of Histologically Identified Delay-Tuned Neurons in the Prefrontal Cortex. Cell Rep 30, 1613-1626 e1614.

Pennington, Z.T., Dong, Z., Feng, Y., Vetere, L.M., Page-Harley, L., Shuman, T., and Cai, D.J. (2019). ezTrack: An open-source video analysis pipeline for the investigation of animal behavior. Sci Rep 9, 19979.

Perea, J.R., Lopez, E., Diez-Ballesteros, J.C., Avila, J., Hernandez, F., and Bolos, M. (2019).

Extracellular Monomeric Tau Is Internalized by Astrocytes. Front Neurosci 13, 442.

Peters, A., and Sethares, C. (2004). Oligodendrocytes, their progenitors and other neuroglial cells in the aging primate cerebral cortex. Cereb Cortex 14, 995-1007.

Poliak, S., and Peles, E. (2003). The local differentiation of myelinated axons at nodes of Ranvier. Nat Rev Neurosci 4, 968-980. 
Pritchett, D., Taylor, A.M., Barkus, C., Engle, S.J., Brandon, N.J., Sharp, T., Foster, R.G., Harrison, P.J., Peirson, S.N., and Bannerman, D.M. (2016). Searching for cognitive enhancement in the Morris water maze: better and worse performance in D-amino acid oxidase knockout (Dao(-/-)) mice. Eur J Neurosci 43, 979-989.

Probst, A., Gotz, J., Wiederhold, K.H., Tolnay, M., Mistl, C., Jaton, A.L., Hong, M., Ishihara, T., Lee, V.M., Trojanowski, J.Q., et al. (2000). Axonopathy and amyotrophy in mice transgenic for human four-repeat tau protein. Acta Neuropathol 99, 469-481.

Quinn, A.J., Lopes-Dos-Santos, V., Huang, N., Liang, W.K., Juan, C.H., Yeh, J.R., Nobre, A.C., Dupret, D., and Woolrich, M.W. (2021). Within-cycle instantaneous frequency profiles report oscillatory waveform dynamics. J Neurophysiol 126, 1190-1208.

Reisel, D., Bannerman, D.M., Schmitt, W.B., Deacon, R.M., Flint, J., Borchardt, T., Seeburg, P.H., and Rawlins, J.N. (2002). Spatial memory dissociations in mice lacking GluR1. Nat Neurosci 5, 868-873.

Rossant, C., Kadir, S.N., Goodman, D.F.M., Schulman, J., Hunter, M.L.D., Saleem, A.B., Grosmark, A., Belluscio, M., Denfield, G.H., Ecker, A.S., et al. (2016). Spike sorting for large, dense electrode arrays. Nat Neurosci 19, 634-641.

Sakakibara, Y., Sekiya, M., Fujisaki, N., Quan, X., and lijima, K.M. (2018). Knockdown of wfs1, a fly homolog of Wolfram syndrome 1 , in the nervous system increases susceptibility to age- and stressinduced neuronal dysfunction and degeneration in Drosophila. PLoS Genet 14, e1007196.

Salib, M., Joshi, A., Katona, L., Howarth, M., Micklem, B.R., Somogyi, P., and Viney, T.J. (2019). GABAergic Medial Septal Neurons with Low-Rhythmic Firing Innervating the Dentate Gyrus and Hippocampal Area CA3. J Neurosci 39, 4527-4549.

Sanchez-Aguilera, A., Wheeler, D.W., Jurado-Parras, T., Valero, M., Nokia, M.S., Cid, E., FernandezLamo, I., Sutton, N., Garcia-Rincon, D., de la Prida, L.M., et al. (2021). An update to

Hippocampome.org by integrating single-cell phenotypes with circuit function in vivo. PLoS Biol 19, e3001213.

Sanderson, D.J., Good, M.A., Skelton, K., Sprengel, R., Seeburg, P.H., Rawlins, J.N., and Bannerman, D.M. (2009). Enhanced long-term and impaired short-term spatial memory in GluA1 AMPA receptor subunit knockout mice: evidence for a dual-process memory model. Learn Mem 16, 379-386. Sanderson, D.J., Gray, A., Simon, A., Taylor, A.M., Deacon, R.M., Seeburg, P.H., Sprengel, R., Good, M.A., Rawlins, J.N., and Bannerman, D.M. (2007). Deletion of glutamate receptor-A (GluR-A) AMPA receptor subunits impairs one-trial spatial memory. Behav Neurosci 121, 559-569.

Schindowski, K., Bretteville, A., Leroy, K., Begard, S., Brion, J.P., Hamdane, M., and Buee, L. (2006). Alzheimer's disease-like tau neuropathology leads to memory deficits and loss of functional synapses in a novel mutated tau transgenic mouse without any motor deficits. Am J Pathol 169, 599-616. Shi, Y., Zhang, W., Yang, Y., Murzin, A.G., Falcon, B., Kotecha, A., van Beers, M., Tarutani, A., Kametani, F., Garringer, H.J., et al. (2021). Structure-based classification of tauopathies. Nature 598, 359-363.

Skaggs, W.E., McNaughton, B.L., Wilson, M.A., and Barnes, C.A. (1996). Theta phase precession in hippocampal neuronal populations and the compression of temporal sequences. Hippocampus 6 , 149-172.

Sri, S., Pegasiou, C.M., Cave, C.A., Hough, K., Wood, N., Gomez-Nicola, D., Deinhardt, K., Bannerman, D., Perry, V.H., and Vargas-Caballero, M. (2019). Emergence of synaptic and cognitive impairment in a mature-onset APP mouse model of Alzheimer's disease. Acta Neuropathol Commun 7, 25.

Steadman, P.E., Xia, F., Ahmed, M., Mocle, A.J., Penning, A.R.A., Geraghty, A.C., Steenland, H.W., Monje, M., Josselyn, S.A., and Frankland, P.W. (2020). Disruption of Oligodendrogenesis Impairs Memory Consolidation in Adult Mice. Neuron 105, 150-164 e156.

Stringer, C., Pachitariu, M., Steinmetz, N., Reddy, C.B., Carandini, M., and Harris, K.D. (2019). Spontaneous behaviors drive multidimensional, brainwide activity. Science 364, 255.

Trivedi, M.A., and Coover, G.D. (2004). Lesions of the ventral hippocampus, but not the dorsal hippocampus, impair conditioned fear expression and inhibitory avoidance on the elevated T-maze. Neurobiology of Learning and Memory 81, 172-184. 
bioRxiv preprint doi: https://doi. org/10.1101/2021.11.24.469849; this version posted November 25, 2021. The copyright holder for this preprint (which was not certified by peer review) is the author/funder, who has granted bioRxiv a license to display the preprint in perpetuity. It is made available under aCC-BY-NC-ND 4.0 International license.

Unal, G., Joshi, A., Viney, T.J., Kis, V., and Somogyi, P. (2015). Synaptic Targets of Medial Septal Projections in the Hippocampus and Extrahippocampal Cortices of the Mouse. J Neurosci 35, 1581215826.

Valero, M., Cid, E., Averkin, R.G., Aguilar, J., Sanchez-Aguilera, A., Viney, T.J., Gomez-Dominguez, D., Bellistri, E., and de la Prida, L.M. (2015). Determinants of different deep and superficial CA1 pyramidal cell dynamics during sharp-wave ripples. Nat Neurosci 18, 1281-1290.

Van der Jeugd, A., Ahmed, T., Burnouf, S., Belarbi, K., Hamdame, M., Grosjean, M.E., Humez, S., Balschun, D., Blum, D., Buee, L., et al. (2011). Hippocampal tauopathy in tau transgenic mice coincides with impaired hippocampus-dependent learning and memory, and attenuated late-phase long-term depression of synaptic transmission. Neurobiol Learn Mem 95, 296-304.

Van der Jeugd, A., Vermaercke, B., Derisbourg, M., Lo, A.C., Hamdane, M., Blum, D., Buee, L., and D'Hooge, R. (2013). Progressive age-related cognitive decline in tau mice. J Alzheimers Dis 37, 777788.

Viena, T.D., Linley, S.B., and Vertes, R.P. (2018). Inactivation of nucleus reuniens impairs spatial working memory and behavioral flexibility in the rat. Hippocampus 28, 297-311.

Viney, T.J., Lasztoczi, B., Katona, L., Crump, M.G., Tukker, J.J., Klausberger, T., and Somogyi, P. (2013). Network state-dependent inhibition of identified hippocampal CA3 axo-axonic cells in vivo. Nat Neurosci 16, 1802-1811.

Viney, T.J., Salib, M., Joshi, A., Unal, G., Berry, N., and Somogyi, P. (2018). Shared rhythmic subcortical GABAergic input to the entorhinal cortex and presubiculum. Elife 7.

Vogel, J.W., Iturria-Medina, Y., Strandberg, O.T., Smith, R., Levitis, E., Evans, A.C., Hansson, O., Weiner, M., Aisen, P., Petersen, R., et al. (2020). Spread of pathological tau proteins through communicating neurons in human Alzheimer's disease. Nature Communications 11, 2612. Wang, X.J. (2002). Pacemaker neurons for the theta rhythm and their synchronization in the septohippocampal reciprocal loop. J Neurophysiol 87, 889-900.

Wang, Y., Romani, S., Lustig, B., Leonardo, A., and Pastalkova, E. (2015). Theta sequences are essential for internally generated hippocampal firing fields. Nat Neurosci 18, 282-288.

Wilson, R.S., Leurgans, S.E., Boyle, P.A., and Bennett, D.A. (2011). Cognitive decline in prodromal Alzheimer disease and mild cognitive impairment. Arch Neurol 68, 351-356.

Wu, D., Gao, D., Yu, H., Pi, G., Xiong, R., Lei, H., Wang, X., Liu, E., Ye, J., Yu, H., et al. (2021). Medial septum tau accumulation induces spatial memory deficit via disrupting medial septum-hippocampus cholinergic pathway. Clin Transl Med 11, e428. 